\title{
Los judíos sevillanos en la Baja Edad Media. Estado de la cuestión y perspectivas de la investigación
}

\author{
Isabel Montes Romero-Camacho *
}

\section{INTRODUCCIÓN}

En el estado actual de nuestros conocimientos, puede resultar incluso pretencioso intentar demostrar el protagonismo alcanzado por la aljama sevillana en los últimos siglos de la Edad Media, cuando de todos es sabido que se trataba de una de las más grandes y brillantes juderías de la Corona de Castilla, situada inmediatamente después de Toledo, la mayor del Reino.

Teniendo en cuenta esta evidencia, tal vez se vea justificada la necesidad de hacer una ligera reflexión acerca de lo que fue su devenir histórico al final de la Edad Media. $\mathrm{O}$, mejor aún, enumerar, aunque sólo sea sumariamente, cuáles son los principales medios e instrumentos de los que podría valerse el posible investigador 0 , simplemente, cualquiera que esté interesado en el tema, para procurar desvelar, al menos, parte de esta historia.

En otro sentido, también podría parecer oportuno, el procurar conocer de qué manera los historiadores que nos han precedido han sabido interpretar las huellas, ya bastante lejanas, dejadas por estos judíos sevillanos, puesto que nuestras perspectivas de futuro, habrán de cimentarse, casi exclusivamente, en los resultados de estas investigaciones.

Serán, pues, estas dos premisas las que nos sirvan de apoyo en las páginas que siguen, cuyo objetivo fundamental no es, ni mucho menos, llevar a cabo una recopilación exhaustiva de todas las fuentes existentes

* Universidad de Sevilla. 
para el estudio de la aljama sevilllana durante los siglos XIII al XVI, ni tampoco de toda la bibliografía publicada sobre el tema hasta nuestros días, sino que, por el contrario, no es otro que tratar de ofrecer, adoptando siempre un radical criterio selectivo, y de la forma más organizada posible, algunos datos útiles para el estudio y conocimiento de los judíos sevillanos, en el otoño de la Edad Media.

\section{LAS FUENTES}

Sin lugar a dudas, cualquier intento de aproximación a la historia de los judíos sevillanos en la Baja Edad Media, ha de partir, necesariamente, de un análisis minucioso de las fuentes conservadas. Afortunadamente, éstas son muy ricas y abundantes, aunque, hoy por hoy, han sido exhumadas y utilizadas sólo a medias.

Dentro de estas fuentes, debemos hacer una clara distinción entre las documentales, en su mayor parte inéditas, y las impresas.

\section{Las fuentes documentales}

Por lo que se refiere a las primeras, y para el caso de la minoría hebrea sevillana, es especialmente importante la documentación conservada en los archivos hispalenses, concretamente en el Archivo de la Santa Metropolitana y Patriarcal Iglesia Catedral de Sevilla, en el Archivo Municipal de Sevilla y en el Archivo de Protocolos sevillano, entre otros.

En el Archivo de la Catedral de Sevilla, que cuenta con un inventario reciente ${ }^{1}$, interesan, especialmente, las secciones:

I. Secretaría.

II. Mesa capitular.

IV. Fábrica.

V. Patronatos y, sobre todo, la denominada.

IX. Fondo histórico general, cuyos doscientos veinte legajos comprenden una variadísima documentación, que comienza en 1248, año de la reconquista de la ciudad, y llega hasta el mismo siglo $x x$.

En cuanto al Archivo Municipal de Sevilla, cuyo ricos fondos docu-

Rubio Merino, P., Inventario de la Santa Metropolitana y Patriarcal Iglesia Catedral de Sevilla. Madrid 1987. 
mentales resultan de fácil acceso ${ }^{2}$, debemos mencionar, particularmente, algunas secciones que guardan una gran cantidad de documentos relacionados con los judíos sevillanos y que, además, están inventariadas o catalogadas total o parcialmente. Así, la Sección 1. ${ }^{a}$ Archivo de privilegios $^{3}$, que tiene como Sección Adjunta, nada menos, que el Tumbo de los Reyes Católicos, donde se comprenden todos los documentos emitidos por la Cancillería Real entre 1474 y $1507^{4}$; Sección 10. ${ }^{a}$ Actas Capitulares ${ }^{5}$; Sección 15. ${ }^{a}$ Papeles del Mayordomazgo ${ }^{6}$; Sección 16. ${ }^{a} \mathrm{Di}-$ versos ${ }^{7}$.

Por último, el Archivo de Protocolos de Sevilla, actualmente en fase de ordenamiento y catalogación, también encierra una gran cantidad de datos relativos a los judíos sevillanos, emanados de sus distintos oficios o escribanías, que han sido rigurosamente extractados por Klaus Wagner ${ }^{8}$.

Realmente, la riqueza de los fondos documentales de estos archivos - por lo que se refiere al desenvolvimiento de la vida de los judíos sevillanos en la Baja Edad Media - es impresionante y, desde luego, pueden considerarse como la fuente primordial para cualquier estudioso que pretenda acercarse a la historia de esta minoría, en la Sevilla de los últimos siglos de la Edad Media. Tal vez sea ésta la razón por la que, hasta la fecha, la mayor parte de los investigadores han centrado su atención, casi exclusivamente, en los archivos locales sevillanos.

Sin embargo, esta historia quedaría muy incompleta si desconociésemos cuál fue la relación de los judíos sevillanos con la corona castellana -más aún si tenemos en cuenta que esta judería fue una de las más

2 Collantes de Teran y Sánchez, A., Guía del Archivo Municipal de Sevilla. Sevilla 1977.

3 VelázQuez y Sánchez, José, Archivo Municipal de Sevilla. Archivo General. Sección Primera. Archivo de Privilegios. Sevilla 1860.

4 Hace tiempo que don Claudio Sanz ARIzMEnd publicó su «índice del Tumbo de los Reyes Católicos", Revue Historique, LXII, n. ${ }^{\circ} 141,1924$, pero afortunadamente hoy contamos con una excelente edición de este Tumbo, que fue dirigida por el Prof. Juan de Mata Carriazo y Arroquia y de la que, hasta el momento se han publicado cinco tomos, que abarcan hasta el año 1492 (Tumbo de los Reyes Católicos del Concejo de Sevilla. Sevilla, t. I, 1928-1968; t. II, 1968; t. III,1 $968 ;$ t. IV, 1968 y t. V, 1971).

5 Sanz Fuentes, María Josefa y Simo Rodríguez, María Isabel, Catálogo de documentos contenidos en los Libros de Cabildo del Concejo de Sevilla. Sevilla 1975.

- Collantes de Teran Delorme, Francisco, Inventario de los Papeles del Mayordomazgo del siglo xIv. Sevilla 1968; Inventario de los Papeles del Mayordomazgo del siglo XV, t. I, 1401-1416. Sevilla 1972 y t. II, 1417-1431. Sevilla 1980.

7 Collantes de Terán Sánchez, Antonio, Archivo Municipal de Sevilla. Catálogo de la Sección 16. ${ }^{\text {, }}$, t. I, 1280-1515. Sevilla 1977.

$\therefore$ WAGNeR, Klaus, Regesto de documentos del Archivo de Protocolos de Sevilla, referentes a judíos y moros. Sevilla 1978. 
ricas e importantes de Castilla- para lo que no contamos con testimonios directos en la documentación sevillana.

Por este motivo, resulta imprescindible analizar los fondos documentales conservados en el Archivo General de Simancas, donde, para la época que tratamos, se custodia gran parte de la documentación relativa a los reyes de Castilla.

Como es sabido, se trata de un Archivo extraordinariamente rico y, afortunadamente, bastante bien organizado, por lo que una simple hojeada a su guía más reciente ${ }^{9}$ nos puede dar una idea aproximada de la gran cantidad de legajos que encierran noticias referentes a los judíos sevillanos del final de la Edad Media.

A este respecto, entre sus diversas secciones, debemos mencionar la Sección I. Patronato Real, especialmente su legajo 28 que comprende documentos relacionados con la Inquisición en Castilla, entre los años 1482 y 1674, según se comprueba en su correspondiente catálogo ${ }^{10}$.

La Sección VI. Cámara de Castilla, donde interesan, sobre todo, sus series Pueblos y Personas y Diversos de Castilla. De la serie Pueblos y Personas nos son especialmente útiles sus primeros 113 legajos, cuya documentación -que se hace seriada a partir de 1477 hasta 1517- ha sido ordenada por apellidos de los individuos y nombres de las poblaciones, como consta en su inventario ${ }^{11}$. La serie Diversos de Castilla comprende una colección miscelánea de documentos, reunidos en 48 legajos y cuyas fechas extremas van del 972 al 1716, donde se incluye, entre otras cosas, la documentación relativa a la expulsión de los judíos ${ }^{12}$.

Particularmente importante para nuestros objetivos es la Sección IX. Registro General del Sello de Corte, extraordinario conjunto documental compuesto por más de 2.400 legajos, donde se recogen documentos fechados entre 1475 y 1689 , y cuya riqueza y variedad, para el tema que nos ocupa, puede ser comprobada con una simple revisión de sus catálogos publicados hasta la fecha ${ }^{13}$.

\footnotetext{
9 Plaza Bores, Ángel de la, Guía del Investigador del Archivo General de Simancas. Madrid 1986.

10 Archivo General de Simancas. Catálogo V. Patronato Real (834-1851). Edición completa. Revisión e índices por Prieto Cantero, Amalia, 2 vols. Valladolid 1946-1949.

11 Archivo General de Simancas. Inventario n. ${ }^{\circ}$ 65: índice de conceptos del grupo documental Cámara: Pueblos y Cámara: Personas.

12 Archivo General de Simancas, Catálogo I: Cámara de Castilla. Diversos de Castilla, por PAZ, Julián, 2. ${ }^{a}$ ed. Madrid 1969.

13 Registro General del Sello. Volumen / (1454-1477), por Ortiz dE MonTALván, Gonzalo. Nueva edición revisada, reformada y preparada por MENDOZA LASALLE, María Asunción. Valladolid 1950; Volumen // (1478-junio 1480), por MENDOZA, María Asunción; PRIETO, Amalia y ÁL-
} 
Igualmente interesante es la Sección XVI. Escribanía Mayor de Rentas, que cuenta con más de 1.000 legajos, distribuidos en las series: 1. Escribanía Mayor de Rentas, 2. Mercedes y Privilegios, 3. Quitaciones de Corte y 4. Nóminas de Corte, que, por regla general, pueden consultarse con facilidad a través de sus inventarios individuales topográficos en fichas. En esta sección aparecen numerosos e importantísimos datos sobre la evolución demográfica, la posición económica, los sistemas sociales y las relaciones de poder de los judíos y conversos sevillanos a lo largo del siglo $x V^{14}$.

Finalmente, debemos referirnos a la Sección XX. Contaduría Mayor de Cuentas. Primera época, donde entre sus casi 2.000 legajos se encuentran muchas noticias interesantes, como las relativas a los bienes de los judíos, especialmente durante el reinado de los Reyes Católicos. Por desgracia, esta sección no resulta ser de muy fácil acceso, ya que sólo existen algunos inventarios antiguos, procedentes de los siglos XVII y XIX, relativamente sumarios ${ }^{15}$.

Sin embargo, a pesar de la abundancia y riqueza de esta documentación simánquina, hoy por hoy, no podemos decir que haya sido ni siquiera suficientemente utilizada y aprovechada, salvo honrosas excepciones, como las representadas por los novedosos y sugerentes trabajos del profesor Miguel Ángel Ladero Quesada, ya sean los relativos al análisis del desarrollo demográfico y de la capacidad económica de las aljamas castellanas a lo largo del siglo xv, o al complejo mundo de los judeoconversos andaluces ${ }^{16}$.

\footnotetext{
VAREZ, Concepción. Valladolid 1951; Volumen III (julio 1480-diciembre 1484), por Prieto, Amalia; Mendoza, María Asunción; Álvarez, Concepción y Represa, Amando. Valladolid 1953; Volumen IV (1485-1486), por Prieto, Amalia; MendozA, María Asunción y Álvarez, Concepción. Valladolid 1956; Volumen V (enero 1487-diciembre 1488), por Prieto, Amalia y Álvarez, Concepción. Valladolid 1958; Volumen VI (enero-diciembre 1489), por PRIETO, Amalia y ÁlvAREZ, Concepción. Valladolid 1959; Volumen VII (enero-diciembre 1490), por PrIETO, Amalia y ÁlvAREZ, Concepción. Valladolid 1961; Volumen VIII (enero-diciembre 1491), por Prieto, Amalia y Álvarez, Concepción. Valladolid 1963. Volumen IX (enero-diciembre 1492), por PrIETo, Amalia y ÁlvAREZ, Concepción. Valladolid 1965; Volumen X (enero-diciembre 1493), por PrIeto, Amalia y Álvarez, Concepción. Valladolid 1967; Volumen XI (enero-diciembre 1494), por Prieto, Amalia y Álvarez, Concepción, Instituto Jerónimo Zurita. Madrid-Valladolid 1970; Volumen XII (enero-diciembre 1495), por Prieto, Amalia y Álvarez, Concepción, Instituto Jerónimo Zurita. Madrid-Valladolid 1974; Volumen XIII (enero-diciembre 1496), por Álvarez Terán, Concepción, Dirección General de Bellas Artes y Archivos. Madrid 1987; Volumen XIV (enero-diciembre 1497), por URQUIJO, María Jesús, Dirección General de Bellas Artes y Archivos. Madrid 1989; Volumen XV (enerodiciembre 1498), por URQUIJO, María Jesús, Dirección General de Bellas Artes y Archivos. Madrid 1989.

${ }_{14}$ Plaza Bores, Ángel de la, Guía del Investigador del Archivo General de Simancas..., págs. 242-244.

15 Ibidem, pág. 270.

16 Ladero Quesada, M. A., "Las juderías de Castilla según algunos servicios fiscales del
} 


\section{Las fuentes impresas}

Pero la historia de los judíos sevillanos al final de la Edad Media también debe basarse en otro tipo de fuentes, en su mayoría impresas, de carácter general para todos los hebreos hispanos y para los castellanos en particular.

Esta realidad fue observada, hace un siglo, por algunos insignes eruditos como el padre Fidel Fita ${ }^{17}$ o Joseph Jacobs ${ }^{18}$. Por tanto es necesario, con el fin de adaptarlas a nuestro propósito, que hagamos una división, bien cronológica o temática, según los casos, de estas fuentes.

Así, ya en el siglo XIII, merecen ser destacadas las fuentes de carácter legislativo, ya se refieran a las relaciones de los judíos con la Iglesia ${ }^{19}$ $o$, sobre todo, a los códigos de leyes vigentes en el reino castellano. Entre ellos debemos citar al Fuero Real ${ }^{20}$ y, muy especialmente, Las Partidas ${ }^{21}$, cuyas leyes relativas a los hebreos han sido glosadas por M. A. Ortí Belmonte ${ }^{22}$.

Evidentemente, el reinado de Alfonso $X$ fue decisivo en cuanto a la historia de los judíos castellanos y así aparece plasmado en muchas de las obras surgidas en el círculo cortesano del Rey Sabio, algunas tan próximas al Rey Poeta como Las Cántigas. Los numerosos datos que éstas

siglo XV", Sefarad, $n .{ }^{\circ} \mathrm{XXXI}, 1971$, págs. 249-264. "Judeoconversos andaluces en el siglo XV", I Congreso Internacional de Encuentro de las Tres Culturas. Toledo 1983. "Judeoconversos andaluces en el siglo XV", III Coloquio de Historia Medieval Andaluza. La sociedad medieval andaluza: grupos no-privilegiados. Jaén 1984, págs. 27-55. "Los conversos de Córdoba en 1497", El Olivo, n. ${ }^{\circ}$ xiii/29-30, 1989, págs. 187-205. Sevilla y los conversos: los «habilitados» en 1495, ponencia presentad al congreso celebrado en Ribadavia, en octubre de 1991. Judíos y judeoconversos en Andalucía. 1481-1508, contribución al congreso mundial sobre la expulsión de los judíos, celebrado en Jerusalén, en enero de 1992.

17 FITA, F., «Historia hebrea. Documentos y monumentos inéditos», Biblioteca de la Real Academia de la Historia (B.R.A.H.), n. ${ }^{\circ} \mathrm{XV}$ l, 1890 , págs. $432-456$ y $555-574$.

18 JACOB, Joseph, An Inquiry into the sources of the History of the Jews in Spain. Londres 1894

19 GrayzeL, Solomon, The Church and the Jews in the XIllth Century. A study of their relations during the years 1198-1254, based on the papal letters and the conciliar decrees of the period, Dropsie College. Philadelphia 1933.

20 Publicado en Los códigos españoles concordados y anotados, 12 vols., 2.. ed., La Publicidad. Madrid 1872-1873. Para su mejor comprensión resulta interesante el trabajo de CERDA RuIz-Funes, Joaquín, "Las glosas de Arias de Balboa al Fuero Real de Castilla», Anuario de

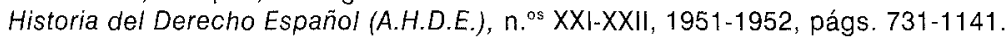

${ }_{21}$ Las Siete Partidas..., cotejados con varios códices antiguos, ed. de la Real Academia de la Historia, 3 vols. Madrid 1807

22 Orti BeLmonte, M. A., «Glosas a la legislación sobre los judíos en Las Partidas», Boletín de la Real Academia de Córdoba de Ciencias, Bellas Letras y Nobles Artes, $n .{ }^{\circ}$ XXVI, 1955 , págs. $41-66$. 
aportan han despertado, desde hace años, el interés de los estudiosos como A. l. Bagby ${ }^{23}$ y Angus Mackay ${ }^{24}$. Pero, quizás, el mejor conocedor de las relaciones de Alfonso X con respecto a los judíos, sea, sin duda, David Romano, según ha demostrado en numerosos e importantes trabajos ${ }^{25}$.

Para el caso concreto de la Sevilla de Alfonso X también contamos con algunas obras de importancia, sobre todo porque publican numerosos y significativos documentos de época alfonsí, relativos a la ciudad. En este sentido, no podemos dejar de mencionar el libro fundamental del profesor Antonio Ballesteros Beretta, escrito a principios de este siglo, y algunos trabajos más modernos, como el de José Damián González Arce ${ }^{26}$. Mención aparte merece el recién publicado Diplomatario Andaluz de Alfonso $X$ el Sabio, bajo la dirección de Manuel González Jiménez, donde aparece recopilada toda la documentación real de época alfonsí, relativa a Andalucía $^{27}$.

Otra fuente importantísima para el estudio de los judíos castellanos durante todo el período histórico que nos ocupa, es decir desde la segunda mitad del siglo XIII hasta principios del siglo XVI, son, indudablemente, las actas de Cortes, cuyas leyes acerca de los judíos han sido estudiadas por Pilar León Tello ${ }^{28}$. Algo semejante puede decirse de la documentación emanada de la Cancillería Real, concretamente la custo-

23 BagBY, Albert I., «Alfonso X el Sabio compara a moros y judíos», Romanische Forschungen, n. ${ }^{\circ}$ LXXXII. Colonia 1970, págs. 578-583. «The Jews in the «Cantigas» of Alfonso X el Sabio", Speculum, n. ${ }^{\circ}$ 46. Cambridge, Mass. 1971, págs. 670-688.

24 Mackay, Angus y HatTon, Vikki, "Anti-semitism in the Cantigas de Santa María", Bulletin of Hispanic Studies, n. ${ }^{\circ}$ LX. Liverpool 1983, págs. 189-199.

${ }_{25}$ Romano, David, “Alfonso $X$ y los judías. Problemática y propuestas de trabajo», presentado al Coloquio sobre Alfonso $X$ y su época que organizara el Centro de Estudios Sociales del Valle de los Caídos. Madrid 1982, y publicado en el Anuario de Estudios Medievales, n. 15. Barcelona 1985, págs. 151-177. Algunas de sus conclusiones también se recogen en «Los judíos y Alfonso $X_{*}$, Revista de Occidente, n. ${ }^{\circ} \mathrm{XI} / 43$, diciembre de 1984, págs. 203-217. Una recopilación de sus trabajos en De Historia Judia Hispánica, «Homenaje al prof. David romano Ventura», n. ${ }^{\circ}$ I. Universidad de Barcelona, 1991.

26 Ballesteros Beretta, Antonio, Sevilla en el siglo xili. Madrid 1913, interesa, especialmente, su riquísimo apéndice documental. GonzÁLEZ ARCE, José Damián, «Cuadernos de or-

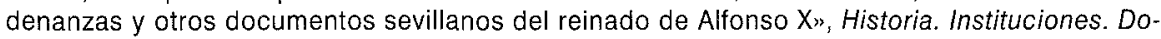
cumentos (H.I.D.), 16. Sevilla 1989, págs. 103-132.

27 GonzÁlez JimÉnEZ, Manuel (ed.), Diplomatario andaluz de Alfonso X el Sabio, «El Monte. Caja de Sevilla y Huelva». Sevilla 1991.

${ }_{28}$ Cortes de los antiguos reinos de León y Castilla. Ed. de la Real Academia de Historia, 7 vols. Madrid 1861-1903. LEÓN TELLo, Pilar, «Legislación sobre los judíos en las Cortes de los Antiguos Reinos de León y Castilla", Fourth World Congress of Jewish Studies, n. ${ }^{\circ}$ II. Jerusalén 1968, págs. 55-63. 
diada en el Archivo General de Simancas, que fue recopilada por Tomás González ${ }^{29}$.

Ya dentro del extraordinariamente rico apartado de las Fuent es Cronísticas, debemos citar, en primer lugar, la edición llevada a cabo por don Cayetano Rossell, para la Real Academia de la Historia, donde se comprenden las crónicas de todos los monarcas castellanos de la Baja Edad Media ${ }^{30}$.

Pero parece conveniente que hagamos un ligero recorrido por los diferentes reinados, citando sus principales cronistas o, en su defecto, las obras de algunos autores que recojan datos de interés, especialmente documentales, sobre ellos.

De esta forma, comenzando por Alfonso X, no podemos dejar de nombrar a la Primera Crónica General de España ${ }^{31}$. Para el reinado de Sancho IV tenemos la obra fundamental de Mercedes Gaibrois de Ballesteros $^{32}$. Fernando IV tuvo su historiador en la persona de A. Benavides ${ }^{33}$, mientras que la Crónica de AlfonsoXI, es atribuida al canciller Fernán Sánchez de Valladolid, el mismo que, según la tradición escribió, por orden de Alfonso XI, Las Tres Crónicas, así llamadas por referirse a los reinados de Alfonso X, Sancho IV y Fernando IV (1252-1312) ${ }^{34}$.

Para la turbulenta época de Pedrol y de los primeros Trastáramas, contamos con una fuente de excepción, el cronista cortesano don Pedro López de Ayala, de quien debemos mencionar, por lo que se refiere a los judios, no sólo sus magníficas reseñas históricas de los reinados de Pedrol, Enrique II, Juan I y Enrique III, sino su famoso Rimado de Palacio ${ }^{35}$. Igualmente es interesante a este respecto la obra de J. Catalina

29 GonzÁlez, Tomás, Colección de cédulas, reales órdenes... Madrid 1829.

3o Rossell, Cayetano, Crónicas de los Reyes de Castilla. Desde don Alfonso el Sabio, hasta los Católicos don Fernando y doña Isabel, "Biblioteca de Autores Españoles (B.A.E.)». Madrid 1953.

31 Primera Crónica General de España, ed. de Menéndez PIDAL, Ramón, 2 vols. Madrid 1955.

32 Gaibrois de Ballesteros, Mercedes, Historia del reinado de Sancho IV de Castilla, 3 vols. Madrid 1922-1928.

33 Benavides, A., Memorias de don Fernando IV de Castilla. Madrid 1860, donde se comprende también la crónica de dicho rey.

${ }_{34}$ Todas ellas se encuentran en la citada edición de Rossell, Cayetano, Crónicas de los Reyes de Castilla..., t. l. Madrid 1953.

35 Para las crónicas, consultar la edición de Rossell, Cayetano, t. I y II. Madrid 1953. En cuanto al Rimado de Palacio, todavía resulta interesante la edición de JANER, Florencio, publicada en la misma "Biblioteca de Autores Españoles», vol. LVII, nueva edición. Madrid 1952. Su aportación histórica en Franco Silva, Alfonso y Romero Tallafigo, Manuel, «Un testimonio de la crisis de la sociedad feudal en el siglo xIv: El «Rimodo de Palacio» de P. López de Ayala», Hispania, n. ${ }^{\circ}$ 149, 1981, págs. 485-513. (Sigue la personalidad de don Pero...). La personalidad de don Pero como cronista fue glosada por SÁNCHez AlBornoz, C., «El Canciller Ayala, historiador», en Españoles ante la historia. Buenos Aires 1958. 
García ${ }^{36}$, así como el siempre sugerente estudio de L. Suárez Fernández sobre este largo y conflictivo período de la historia castellana que tuvo en el canciller un testigo de excepción ${ }^{37}$.

En lo que concierne al reinado de Juan II, encontramos noticias de interés sobre la política regia en relación a los judíos de Castilla en algunos renombrados cronistas como Alvar García de Santa María, Fernán Pérez de Guzmán o en la llamada Crónica del Halconero de Juan $/{ }^{38}$.

Por su parte, el problemático gobierno de Enrique IV cuenta con las crónicas de Alonso de Palencia, Mosén Diego de Valera, Diego Enríquez del Castillo y Luis Galíndez de Carvajal ${ }^{39}$.

Por último, la actuación de los Reyes Católicos, con respecto a los judíos, nos es conocida gracias, sobre todo, a dos extraordinarios cronistas: Andrés Bernáldez, cura de Los Palacios y Hernando del Pulgar ${ }^{40}$.

Ya para un ámbito más local, destacaríamos la obra de Benito de Cárdenas sobre la historia jerezana del siglo $\mathrm{XV}^{41}$.

36 Catalina García, J., Castilla y León durante los reinados de Pedro I, Enrique II, Juan ly Enrique III. Madrid 1892.

${ }_{37}$ SuÁrez Fernández, L., El Canciller Pero López de Ayala y su tiempo (1332-1407). Vitoria 1962.

38 Carriazo y Arroquia, Juan de Mata, Crónica de Alvar García de Santa María. Sevilla 1947. Pérez de Guzmán, Fernán, Crónica de Juan II, edición de don Cayetano Rossell para la «Biblioteca de Autores Españoles» de la Real Academia de la Historia. Madrid 1953. Crónica del Halconero de Juan II, edición de Juan de Mata Carriazo y Arroquia. Madrid 1946.

39 Palencia, Alonso de, Crónica de Enrique $N$, en latín, traducción castellana de A. Paz y Melià. Madrid 1904-1909, ver también PAZ Y MELIA, A., El cronista Alonso de Palencia. Su vida y sus obras; sus Décadas y las Crónicas contemporáneas; ilustraciones de las Décadas y notas varias. Madrid 1914. Igualmente hay una edición de esta crónica en la "Biblioteca de Autores Españoles», Crónicas de los Reyes de Castila, t. I, II y III. Madrid 1975. VaLeRA, Mosén Diego de, Memorial de las diversas hazañas. Crónica de Enrique $N$, edición y estudio de Juan de Mata Carriazo y Arroquia. Madrid 1941 y en la «Biblioteca de Autores Españoles», t. III. Madrid 1953. Enríquez del Castillo, Diego, Crónica del rey don Enrique $I V$, asimismo en la «Biblioteca de Autores Españoles", t. III. Madrid 1953. Galíndez DE CARVAJAL, L., Crónica de Enrique $N$, edición y estudio de J. Torres Fontes, C.S.I.C., "Seminario de Historia de la Universidad Murciana", 1946.

40 Bernáldez, Andrés, cura de Los Palacios, Historia de los Reyes Católicos don Fernando y doña Isabel. «Biblioteca de Autores Españoles», Crónicas de los Reyes de Castilla, t. III. Madrid 1953 y Memorias del reinado de los Reyes Católicos, ed. de M. Gómez Moreno y J. de M. Carriazo y Arroquia. Madrid 1962 y "Biblioteca de Autores Españoles», Crónicas de los Reyes de Castilla, t. III. Madrid 1953. Pulgar, Hernando del, Crónica de los Reyes Católicos (por su secretario Fernando del Pulgar), ed. y estudio por J. de M. Carriazo y Arroquia. Madrid 1943 y "Biblioteca de Autores Españoles", Crónicas de los Reyes de Castilla, t. III. Madrid 1953.

${ }^{41}$ Cárdenas, Benito de, Cronicón de Jerez, ed. en Moreno de Guerra, Juan, Bandos de Jerez, I. Madrid 1929. 


\section{Obras relativas a la historia de Sevilla}

Como es lógico pensar, antes de iniciar cualquier intento de acercamiento a la historia de los judíos sevillanos, es obligado conocer, de la manera más pormenorizada posible, los principales hitos de la historia de Sevilla a partir de la conquista cristiana. Afortunadamente los estudios de la llamada "historia local» han tenido numerosos y, lo que es más difícil, notables cultivadores, a veces, desde hace más de cuatrocientos años. Los más importantes de ellos aparecen reseñados en el estudio de Juan Pérez de Guzmán, publicado a principios de este siglo ${ }^{42}$, aunque, desde luego, los mejores y más completos repertorios bibliográficos al efecto pueden encontrarse en algunas obras de Miguel Ángel Ladero Quesa$\mathrm{da}^{43}$.

Pero, a pesar de contar con estas utilísimas publicaciones de consulta, no nos resistimos a citar aquí a algunos venerables historiadores sevillanos que supieron aportar a las generaciones posteriores, no sólo obras de gran rigor histórico y abundancia de noticias, sino una narración amena y perfectamente inteligible. Entre los más antiguos, reseñaremos a Alonso Morgado y, sobre todo, al gran analista y padre, en cierto modo, de toda una larga tradición historiográfica sevillana, Diego Ortiz de Zúñiga ${ }^{44}$. Sus principales continuadores proceden ya de la segunda mitad del siglo XIX, como Justino Matute y Gaviria y Joaquín Guichot Parody, a quienes sucedió, en la primera mitad de este siglo, Joaquín Hazañas ${ }^{45}$.

Pasando ya a la bibliografía relativa a la historia sevillana por épocas, destacaremos, en primer lugar, el clásico estudio de Julio González sobre el Repartimiento de Sevilla, al que debemos sumar el de Manuel González Jiménez y Antonio González Gómez sobre el Repartimiento de Jerez ${ }^{46}$.

42 Pérez de GuZMÁn, Juan, Historiadores del reino de Sevilla. Madrid 1909.

43 Ladero Quesada, Miguel Ángel, Andalucia en el siglo XV. Estudios de historia política. Madrid 1974. "La investigación histórica sobre Andalucía medieval en los últimos veinticinco años", I Congreso de Historia de Andalucia. Córdoba 1978, Andalucía Medieval, 1, págs, $217-$ 250. "Sobre la génesis medieval de la identidad andaluza», en Los mudéjares de Castilla y otros estudios de Historia Medieval Andaluza. Granada 1989, págs. 221-256.

44 Morgado, Alonso, Historia de Sevilla, 1587. OrTIZ de ZúñIGA, Diego, Anales eclesiásticos y seculares de la muy noble y muy leal ciudad de Sevilla. Madrid 1677, reed. Sevilla 1988.

45 Matute y Gaviria, Justino, Noticias relativas a la Historia de Sevilla, que no constan en sus anales. Sevilla 1866. GuICHOT PAROdY, Joaquín, Historia de la ciudad de Sevilla y pueblos de su provincia desde los tiempos más remotos hasta nuestros días, 8 vols. Sevilla 1875-1892. Hazañas y LaRua, Joaquín, Historia de Sevilla. Curso breve en diez lecciones explicadas en la Academia de Estudios Sevillana. Sevilla 1932.

${ }_{46}$ GonzÁLEZ, Julio, Repartimiento de Sevilla. Madrid 1951. GonzÁLez JiMÉnEZ, M. y GonzÁleEZ Gómez, A., Repartimiento de Jerez. Cádiz 1980. 
Junto a la edición y análisis de estas fuentes importantísimas (en muchos casos) imprescindibles para el conocimiento de la historia del Reino de Sevilla a raíz de la conquista, debemos sumar otra obra clave, que igualmente aporta un enorme y rico corpus documental. Nos referimos al libro de Antonio Ballesteros Beretta sobre la Sevilla del siglo XIII ${ }^{47}$. Ya para el siglo XIV sevillano contamos con él, renovador en su época y todavía hoy plenamente vigente, estudio de Ramón Carande Tovar, que igualmente incluye importantes noticias documentales, además de una aguda interpretación histórica ${ }^{48}$. Por último, el siglo $x v$ sevillano también cuenta con dos fuentes de excepción, gracias, una vez más, al desvelo de Juan de Mata Carriazo y Arroquia ${ }^{45}$.

\section{BIBLIOGRAFÍA}

Historia de los judíos y del judaísmo

Dentro de este apartado reseñaremos únicamente ciertas obras que puedan ser útiles, como una primera aproximación al tema, a todos aquéllos que pretendan acercarse al conocimiento de los judíos peninsulares, ya que, antes de profundizar en él, resulta absolutamente imprescindible haber adquirido una formación básica.

En este sentido -y tomándolo como un manual general, altamente didáctico - habría que destacar la historia de los judíos, dirigida por $\mathrm{H}$. H. Ben-Sasson ${ }^{50}$, así como las partes correspondientes a la ambiciosa obra titulada Grandes épocas e ideas del pueblo judio ${ }^{51}$. Y como repertorio bibliográfico y por su tono enciclopédico, debemos recoger el libro de Carlos del Valle ${ }^{52}$.

47 Ballesteros Beretta, A., Sevilla en el siglo xill. Madrid 1913.

48 Carande Tovar, Ramón, "Sevilla, fortaleza y mercado", Anuario de Historia del Derecho Español, II, 1925, págs. 233-401, reed. en Sevilla 1975, nuevamente reeditado por la Universidad de Sevilla en 1989.

49 Carriazo y Arroquia, Juan de Mata, «Anecdotario sevillano del siglo xv. De la crónica de Alvar García de Santa María». Sevilla 1947. «Anecdotario sevillano del siglo xv. De los Anales de Garci Sánchez, jurado de Sevilla", Anales de la Universidad Hispalense, vols. XIV y XV. Sevilla 1953 y 1958.

50 Ben-SAsson, H. H. (dir.), Historia del pueblo judío, Alianza Editorial. Madrid-Barcelona 1988.

51 Editada por Paidós. Buenos Aires 1964, reeditada en 1975, en la Biblioteca del hombre contemporáneo (n.. ${ }^{\text {os }}$ 264-267): I. KaUfMANN, I. "La época bíblica». II. MARCUS, R., «La época helenística». III. COHEN, G. D., "La época talmúdica». IV. HALKIN, A. S., "La época judeoislámica». RotH, V. C., "La época europea", y VI. BARON, S. W., "La época moderna».

52 VALLE, Carlos del, El mundo judío, U.N.E.D. Madrid 1976. 
Por lo que se refiere al judaísmo como realidad histórica, cultural y religiosa, contamos con una aproximación, clara y perfectamente asequible, en la ya clásica obra de Isidore Epstein ${ }^{53}$, que puede completarse, sobre todo en cuanto a su carácter pedagógico, con trabajos posteriores, que han tenido una considerable difusión ${ }^{54}$, mientras que J. G. Frazer ha logrado una atractiva reconstrucción de la vida diaria del pueblo judío durante los tiempos bíblicos a través de su libro sobre el folklore en el Antiguo Testamento ${ }^{55}$.

\section{Obras de interpretación sobre la presencia judía en España}

Como es sabido, el problema de la influencia de la comunidad judía en la conformación del ser histórico de España, ha venido preocupando a numerosos estudiosos, que, muchas veces, han sostenido posturas encontradas al respecto. Ninguna más conocida que la polémica que enfrentó, a mediados del siglo $\mathrm{xx}$, a dos intelectuales de gran talla, uno procedente del campo de la filología, Américo Castro, y el segundo un gran historiador, Claudio Sánchez Albornoz.

La firme defensa de Américo Castro sobre el papel determinante representado por los hebreos a lo largo de la historia hispánica, aparece ya planteada en su obra titulada España en su historia: cristianos, moros y judíos, aunque alcanza su punto culminante en su famoso libro La realidad histórica de España - en el que E. Asensio ha pretendido descubrir sus cualidades de historiador-para volver a exponer la misma tesis en un ensayo que lleva por título De la edad conflictiva ${ }^{56}$.

En cuanto a Claudio Sánchez Albornoz, éste manifestó su radical oposición a las tesis de Castro en numerosos trabajos, siendo recogidos, los más importantes de ellos, en su monumental obra España, un enigma histórico ${ }^{57}$.

53 EPSTAIN, Isidore, Judaism. A historical presentation, Penguin Books. Londres 1959.

54 Como los de Wouk, Hermann, Este es mi Dios, Plaza y Janés. Barcelona 1963. RoseNBERG, Stuart E., El judaísmo, Mensajerc. Bilbao 1969. MuCHNIK, Mario, Mundo judio: crónica personal, Lumen. Barcelona 1983. Rosenserg, Shalom y BeCKERman, Tzvi, Bar-Mitzvá: Trece charlas sobre judaísmo, Universidad Abierta de Israel. Tel-Aviv 1984.

${ }_{55}$ FRAZER, J. G. El folklore en el Antiguo Testamento, Fondo de Cultura Económica. Madrid 1981.

56 Castro, A., España en su historia: cristianos, moros y judios. Buenos Aires 1948. La realidad histórica de España. México 1954. AsENSIO, E., "Américo Castro historiador: reflexiones sobre la realidad histórica de España", Modern language notes, n. $^{\circ}$ 81, 1966 , págs. 595-637. CAStro, A., De la edad conflictiva. Madrid 1961.

57 Sánchez Albornoz, Claudio, España, un enigma histórico. Buenos Aires 1956. 
Pero también otros muchos investigadores se han preocupado de esta cuestión. Algunos tan reconocidos como Marcel Bataillon que lanzó la hipótesis de la influencia del erasmismo en los humanistas hispanos, algunos de posible origen converso ${ }^{58}$.

A lo largo del tiempo, han sido muchos los que han intentado seguir la huella de estos maestros, rastreando la impronta judía en numerosos aspectos de la cultura española ${ }^{59}$. Pero, tal vez, haya sido Emilio Mitre Fernández quien ha vuelto a renovar la antigua polémica, desde un punto de vista estrictamente historiográfico, sobre las dificultades de la convivencia, bien entre cristianos y judíos o entre las tres comunidades que conformaron la historia de España medieval ${ }^{60}$.

Una problemática semejante se vislumbra en numerosos y muy diferentes trabajos de la última década, entre los que merece la pena que citemos los de José Luis Lacave, A. Eban y F. Aznar ${ }^{61}$. Ya por lo que se refiere al ámbito andaluz, este problema ha sido recientemente tratado por Manuel González Jiménez ${ }^{62}$.

\section{Historia de los judíos españoles}

Cualquier intento de aproximación al devenir histórico de los judíos españoles ha de partir, sobre todo en una primera fase, de la consulta sistemática del gran repertorio bibliográfico de Robert Singerman, por más que haga ya algunos años de su publicación ${ }^{63}$. Afortunadamente, contamos con otra guía bibliográfica, igualmente valiosa, pero más moderna y publicada en castellano, gracias a Enrique Cantera Montenegro ${ }^{64}$.

58 Batalllon, Marcel, Erasmo y España. México 1966.

59 Pérez Castro, Federico, «España y los judíos españoles. Interpretación de algunos aspectos de su cultura", capítulo del libro The Sephardi Heritage, vol. I. Londres 1971, págs. 275313. Gonzalo MaEso, David, El legado del judaismo español, Editora Nacional. Madrid 1972.

go Mitre Fernández, E., Judaísmo y cristianismo. Raices de un gran conflicto histórico. Madrid 1980. Cristianos, musulmanes y hebreos. La difícil convivencia de la España medieval. Madrid 1988.

${ }_{61}$ LACAVE, José Luis, Sefarad, Sefarad: La España judía, Comisión Quinto Centenario. Barcelona 1987. Eban, A., Legado: La civilización y los iudíos, Sheva. Madrid 1987. Aznar, F., España medieval: Musulmanes, judíos y cristianos. Madrid 1990. TedeschI, Mario, Polémica y convivencia de las tres religiones. "Colecciones Mapfre 1492". Madrid 1992.

62 González Jiménez, Manuel, «El final de la convivencia. Moros y judíos en Andalucía (siglos XIII-XV)», en Proyección Histórica de España en sus tres culturas (Castilla y León, América y el Mediterráneo. Medina del Campo, abril de 1991 (en prensa).

${ }_{63}$ Singerman, Robert, The Jews in Spain and Portugal, Garland. Nueva York 1975.

${ }^{64}$ Cantera Montenegro, Enrique, "Los judíos en la Edad Media hispana», Cuadernos de Investigación Medieval, Guía crítica de temas históricos. Madrid 1986. 
Pasando ya al análisis de la historia de los judíos hispánicos, debemos decir que, afortunadamente, podemos servirnos de magníficas obras de síntesis -algunas de ellas muy profundas y de gran aparato crítico- y que, además, suelen reseñar y, en muchos casos publicar, numerosas e importantes fuentes, principalmente documentales, que, hasta entonces, habían permanecido inéditas. Por todo ello, y a pesar de que la gran mayoría de estos libros son muy antiguos, el paso del tiempo, en la mayor parte de los casos, no ha hecho sino revalorizarlos y mantenerlos de actualidad, convirtiéndolos en verdaderos clásicos. Los citaremos procurando respetar un orden cronológico.

En este sentido, debemos comenzar por J. Amador de los Ríos, que, en el último cuarto del siglo pasado, publicó su importante libro sobre los judíos peninsulares, tratando de recoger no sólo los avatares de su historia política, sino también numerosos datos sobre su organización social y su comportamiento religioso ${ }^{65}$. Igualmente interesantes, aunque, a veces, algo superados, son los numerosos trabajos que el padre Fidel Fita publicase en el Boletín de la Real Academia de la Historia, especialmente en los últimos veinte años del siglo xIx, que fueron refundidos en su libro La España Hebrea ${ }^{66}$.

Pero entre todos los autores de síntesis sobre la historia de los judíos españoles, destaca, sin lugar a dudas, Baer, cuyas extraordinarias aportaciones no sólo han servido de inspiración, sino de estructura básica, a varias generaciones de historiadores y sin que, hasta la fecha, hayan sido superadas en modo alguno. En primer lugar citaremos, su primera gran obra, escrita en alemán con el nombre de Frit Baer, en la que no sólo recogía una gran cantidad de documentos sobre los judíos españoles, conservados en numerosos archivos peninsulares y otras fuentes de diversa procedencia, sino que, bien la regesta o la publicación íntegra de esta documentación, iba acompañada de un impresionante aparato crítico.

La importancia de esta extraordinaria aportación, que, al parecer, fue conocida muy pronto en España, queda manifiesta en la reseña que José María Millás Villacrosa le dedicó, pocos años después de su publicación $y$ en unas circunstancias no especialmente fáciles ${ }^{67}$.

65 Amador de los Ríos, J., Historia social, política y religiosa de los judíos de España y Portugal. Madrid 1875-1876, reedición en Madrid 1960, Ed. Aguilar y otra en 1984, Ed. Turner.

66 Entre sus artículos del Boletín de la Real Academia de la Historia, podríamos destacar, por ejemplo, el titulado "Nuevos datos para escribir la historia de los judíos españoles», en el t. XV (1889). Y «La España Hebrea». Madrid 1990.

${ }_{67}$ BAER, Fritz, Die Juden im Christlichen Spanien. Erster Teil: Urkunden und Regesten, 2 vols. Berlín 1929-1936. Reedición a cargo de Haim Beinart, en Gregg International, 2 vols. In- 
Posteriormente, ya en Estados Unidos y llamándose Yitzhak Baer, publicó una magnífica obra de síntesis con el mismo título, traducida, hace unos años, al castellano por José Luis Lacave, quien le añadió decisivas contribuciones, sobre todo en lo que se refiere a la puesta al día de la bibliografía y en procurar hacer perfectamente accesible el texto a los investigadores españoles ${ }^{68}$.

También en Estados Unidos fue publicado otro importante libro sobre los judíos españoles en la Edad Media, que intentaba abarcar los diferentes aspectos políticos, sociales y culturales de su desenvolvimiento histórico durante este período y del que fue autor A. A. Neuman ${ }^{69}$. Sus planteamientos siguen siendo válidos aún hoy en día, pero, sobre todo, nos resultan especialmente valiosos los numerosos datos de todo tipo que recoge.

En cuanto a las obras de síntesis debidas a autores españoles, cabe. mencionarse el primer intento de este tipo, más o menos contemporáneo a los autores extranjeros anteriormente citados, llevado a cabo por A. Jiménez Soler, aunque manteniendo siempre un carácter de simple aproximación al tema y haciendo un mayor hincapié en la dinámica histórica de los judíos aragoneses ${ }^{70}$. Por tanto, no sería hasta treinta años más tarde cuando realmente se pueda hablar de una buena síntesis de este tipo, debida a la experiencia investigadora en el tema de Luis Suárez Fernánde ${ }^{71}$. Más recientemente se ha publicado una nueva obra de carácter divulgativo, destinada a lectores no iniciados y debida a Marta López Ibor $^{72}$. Finalmente, como colofón a la historia medieval de los judíos hispanos, citaremos la ambiciosa obra de Julio Caro Baroja sobre los judíos en la España moderna y contemporánea ${ }^{73}$.

glaterra 1970. Nos interesa, sobre todo el t. II: Kastilien/ Inquisitionsakten. MILlAS VILlaCfosa, J. M. ${ }^{a}$, «Historia de los judíos españoles», en Sefarad, n. ${ }^{\circ} 2,1945$.

68 BAER, Yitzhak, A History of the Jews in Christian Spain. Filadelfia 1961, traducida por José Luis Lacave: Historia de los judios en la España Cristiana. Madrid 1981.

69 Neuman, A. A., The Jews in Spain. Their social, political and cultural life during the middle Ages, 2 vols. Filadelfia 1944. Una aportación reciente es la de REINART, Haim, Los judíos en España. «Colección Mapfre. 1492». Madrid 1992.

70 JIMÉnez SOlER, A., Los judíos españoles a fines del siglo XIV y principios del siglo XV. Universidad, XXVII. Zaragoza 1950, págs. 361-414.

71 Suárez Fernández, Luis, Judíos españoles en la Edad Media. Madrid 1980.

72 López IBOr, Marta, Los judios en España, Colección Biblioteca Básica de Historia, Anaya. Madrid 1990.

73 Caro Baroja, J., Los judíos en la España Moderna y Contemporánea, 3 vols., Arion. Madrid 1962; reed. Itsmo. Madrid 1978. 
Aspectos concretos de la historia de los judios españoles

Han sido varios los aspectos concretos de la historia de los judíos españoles que han llamado la atención de los especialistas. A este respecto, merece la pena que citemos, en primer lugar la notable, aunque a veces dispersa obra, de uno de los principales impulsores de los estudios hebraicos en España, a mediados del siglo XX, el profesor Francisco Cantera Burgos, cuyas publicaciones fueron recopiladas, con posterioridad, en un riguroso artículo de José Luis Lacave ${ }^{74}$. Pasando ya a algunos de los temas específicos que han interesado a los estudiosos, citaremos, en primer lugar, aquéllos que tienen una relación, más o menos directa, con los restos arqueológicos que se nos han conservado, como huellas materiales de la presencia judía en la Península. Dentro de este apartado debemos incluir los diferentes estudios de Francisco Cantera Burgos sobre algo tan importante para comprender la historia del pueblo judío, como la sinagoga ${ }^{75}$, así como sus investigaciones sobre los cementerios ${ }^{76}$. Algo semejante puede decirse de la epigrafía, donde debemos mencionar los utilísimos trabajos pioneros de M. Schwab ${ }^{77}$, continuados, entre otros, por Francisco Cantera Burgos y José María Millás Vallicrosa ${ }^{78}$. Más recientemente, José Luis Lacave ha llevado a cabo una puesta al día sobre los hallazgos arqueológicos relacionados con los judíos españoles ${ }^{79}$.

Reîiriéndonos ya a otro tipo de temática, debemos a Haim Beinart una breve síntesis sobre las principales características de la sociedad hispanojudía ${ }^{80}$, mientras que otros rasgos identificativos del pueblo judío también han interesado a un buen número de investigadores, como sus ritos y

\footnotetext{
${ }^{74}$ LACAVE, José Luis, «Bibliografía del Profesor Fancisco Cantera Burgos», Sefarad, n. ${ }^{\circ}$ XXXVII. Madrid 1977, págs. 5-104.

75 Cantera Burgos, F., Sinagogas españolas. Con especial estudios de la de Córdoba y la toledana de El Tránsito. Madrid 1955. Es particularmente interesante, como obra de síntesis, su aportación al Simposio Toledo Judaico, titulado «La Sinagoga» y publicado en el vol. I de las Actas. Centro Universitario de Toledo 1973, págs. 7-27. Estos estudios han sido recientemente renovados por su discípulo José Luis LACAVE, Juderias y Sinagogas españolas, «Colecciones Mapfre 1492». Madrid 1992.

76 Cantera Burgos, F., "Cementerios hebreos en España", Sefarad, n. ${ }^{\circ}$ XIII, 1953.

77 SCHWAB, M., Rapport sur les inscriptions hebraiques d'Espagne. París 1907.

78 Cantera Burgos, F. y Millas Vallicrosa, José María, Las inscripciones hebraicas en España. Madrid 1956.

79 LACAVE, José Luis, “Restos arqueológicos de los judíos en España». Encuentros en Sefarad, Instituto de Estudios Manchegos. Ciudad Real 1987, págs. 25-32.

80 BeINART, Haim, "Hispano-Jewish Society», Cahiers d'Histoire Mondiale, n. ${ }^{\circ} \mathrm{XI}, 1968$, págs. $220-238$
} 
costumbres $^{81}$ o la influencia hebrea en la literatura o la ciencia española ${ }^{82}$.

\section{Historia de los judíos españoles}

Recogeremos aquí algunos trabajos que pueden considerarse como más significativos y, sobre todo, más útiles, acerca de la historia de la judíos castellanos en la Baja Edad Media, bien porque se refieran específicamente a ellos o bien porque se trate de datos comprendidos en obras de síntesis. Con este fin, volveremos a adoptar un orden cronológico.

En primer lugar, debemos mencionar las obras de David Romano, ya citadas, sobre las relaciones entre Alfonso X y los judíos ${ }^{83}$. Por su parte Salvador de Moxó se interesó por la historia de los judíos castellanos de la primera mitad del siglo XIV, haciendo hincapié, como especialista de este reinado, en los tiempos de Alfonso $\mathrm{XI}^{84}$. En otro sentido, la supuesta postura proteccionista de Pedro I, con relación a los judíos, ha sido tratada por Luis Vicente Díaz Martín ${ }^{85}$, mientras que la instauración en el trono de la dinastía Trastámara y su ambivalente política con respecto a los judíos, han encontrado su historiador en J. Valdeón Baruque ${ }^{86}$. Dentro de

81 Santamaría, R., "Ritos y costumbres de los hebreos españoles", Boletín de la Real Academia de la Historia, n. ${ }^{\circ}$ XII. Madrid 1893 y, más recientemente, LEÓN Telto, Pilar, "Costumbres, fiestas y ritos de los judíos toledanos a fines del siglo XV," Simposio Toledo Judaico, II. Toledo 1973 y CANTERA MONTENEgro, Enrique, "Solemnidades, ritos y costumbres de los judaizantes de Molina de Aragón a fines de la Edad Media", /I Congreso Internacional. Encuentro de las Tres Culturas. Toledo 1985.

82 Millas VALLICROSA, José Maria, Literatura hispano-hebrea, Labor. Barcelona 1967. NAVARRo, Ángeles, Literatura hispano-hebrea (siglos X-XIII): Panorámica, El Almendro. Córdoba 1988. MILLAS VALLICROSA, José María, Estudio sobre la historia de la ciencia española, 2 vols., C.S.I.C. Barcelona, reimpr. facs. 1987 (interesan particularmente los capítulos VIII-XI y XVI del vol. primero y los caps X, XIII-XVI del vol. II). Romano, David, La ciencia hispanojudía. «Colección Mapfre 1992». Madrid 1992.

33 Romano, David, «Alfonso $X$ y los judícs. Problemática y propuestas de trabajo», ponencia presentada al Coloquio sobre Alfonso X y su epoca, celebrado en el Centro de Estudios Sociales del Valle de los Caídos. Madrid 1982, cuyas conclusiones recogería más tarde en "Los judíos y Alfonso X», Revista de Occidente, $n .^{\circ} \mathrm{Xl} / 43$, diciembre de 1984, págs. 203-217 y, especialmente, "Alfonso $X$ y los judíos. Problemática y propuestas de trabajo", Anuario de Estudios Medievales, n. ${ }^{\circ} 15,1985$, págs. 151-177. Más recientemente existe otra edición de este último trabajo en De Historia Judía Hispánica, en «Homenaje al profesor David Romano Ventura", I, Universidad de Barcelona, 1991.

${ }_{84}$ Moxo, Salvador de, "Los judíos castellanos en la primera mitad del siglo XIV", Simposio Toledo Judaico, I. Toledo 1973. "Los judíos castellanos en el reinado de Alfonso X1", Sefarad, n. ${ }^{\text {ss }}$ XXXV, 1975, págs. 131-150 y XXXVI, 1976, págs. 37-120.

85 Díaz Martín, Luis Vicente, Itinerario de Pedro / de Castilla. Estudio y Regesta. Valladolid 1975. Los oficiales de Pedro I de Castilla. Valladolid 1975.

${ }^{86}$ VALDEÓN BARUQUE, J., Enrique II de Castilla: La guerra civil y la consolidación del régimen (1366-1371). Valladolid 1966. "Notas sobre las mercedes de Enrique II de Castilla», Hispania, n. ${ }^{\circ}$ XXVIII, 1968, págs. 38-55. Los judíos de Castilla y la revolución Trastámara. Valladolid 1968. 
este mismo aspecto, es interesante el análisis de Luis Suárez Fernández sobre Juan I de Castilla ${ }^{87}$. Finalmente, Emilio Mitre Fernández, ha estudiado el problema judío durante el gobierno de Enrique III $^{88}$. Tal vez, entre las principales aportaciones de estas investigaciones, además por supuesto, de sus brillantes interpretaciones sobre el problema, se cuente el hecho de que, muchas de ellas, incluyen una colección diplomática, más o menos completa, del reinado en cuestión.

\section{Historia de algunas}

En este apartado, antes de recoger diversos estudios sobre determinadas aljamas castellanas, debemos citar algunas obras de síntesis de enorme interés, como las de M. A. Ladero Quesada, quien ha partir de fuentes hacendísticas del siglo XV, relativas a la Corona de Castilla, ha podido deducir numerosos e importantes datos, especialmente demográficos y económicos, sobre un buen número de juderías castellanas ${ }^{89}$.

Pasando ya a la enumeración de estudios concretos sobre ciertas aljamas de Castilla, debemos citar el de Francisco Cantera Burgos sobre la de Burgos ${ }^{90}$, el de J.Rodríguez Fernández, sobre las de León y su provincia $^{91}$, el de A. Carlos Merchán Fernández sobre la de Valladolid ${ }^{92}$, los de Pilar León Tello sobre los judíos de Ávila, Palencia y, sobre todo, Toledo ${ }^{93}$, judería a la que también han dedicado su atención Julio Valdeón Baruque y José Manuel Nieto Soria ${ }^{94}$. Sobre las juderías de La Rioja,

${ }^{87}$ SuÁRez Fernández, Luis, Historia del reinado de Juan / de Castilla, 2 vols. Madrid 19771982.

38 Mitre Fernández, E., “Los judíos y la Corona de Castilla en el tránsito al siglo xv», Cuadernos de Historia, III. Madrid, 1969, págs. 347-368.

89 LADERO QueSADA, M. A., "Las juderías de Castilla según algunos servicios fiscales del siglo Xv», Sefarad, n. ${ }^{\circ}$ XXXIII, 1971, 249-264. La Hacienda Real de Castilla en el siglo XV. La Laguna de Tenerife 1973. "Los judíos castellanos del siglo XV en el arrendamiento de impuestos reales», Cuadernos de Historia, n. ${ }^{\circ} \mathrm{V}$, 1975, págs. 417-439.

9o Cantera Burgos, F., Alvar Garcia de Santa Maria. Historia de la Judería de Burgos y sus conversos más egregios, C.S.I.C. Madrid 1952.

91 Rodriguez FennÁNDEZ, J., La judería de la ciudad de León, C.S.I.C. León 1969. Las juderías de la provincia de León, C.S.I.C. León 1976.

92 Merchan Fernández, A. Carlos, Los judios de Valladolid, Diputación Provincial. Valladolid 1976.

93 León Tello, Pilar, Judios de Ávila, Diputación Provincial. Ávila 1963. «Los judíos de Palencia", Publicaciones del Instituto Tello Téllez de Meneses, n. ${ }^{\circ}$ 25. Palencia 1967, págs. 1-169. Judios de Todelo, C.S.I.C., Instituto Arias Montano, 2 vols. Madrid 1979.

94 Valdé́n Baruque, J., «La judería toledana en la guerra civil de Pedro I y Enrique Il», Simposio Toledo judaico, I. Toledo 1972, págs. 107-131. NIETo SorIA, José Manuel, “Los judíos de Toledo en sus relaciones financieras con la monarquía y la Iglesia (1252-1312)», Sefarad, $n^{\circ}{ }^{\circ} \mathrm{XLI}, 1981$, págs. $301-319$ y XLII, 1982, págs. 79-102. 
contamos con el exhaustivo estudio de Enrique Cantera Montenegro ${ }^{95}$. También siguen siendo válidos, a pesar del tiempo transcurrido desde su publicación, los trabajos del padre Fidel Fita sobre las juderías de Madrid y de Segovia ${ }^{96}$. La historia de los judíos murcianos nos es conocida gracias a los trabajos de Juan Torres Fontes y de Ángel Luis Molina Molina y Francisco de Lara Fernández ${ }^{97}$.

Pasando ya a las juderías andaluzas, citaremos, en primer lugar algunos estudios, bien a nivel general, como los de A. Collantes de Terán y Haim Beinart ${ }^{98}$ o el de María Antonia Bel Bravo, localizado en el reinado de los Reyes Católicos ${ }^{99}$. Por último, dejando aparte las aljamas del reino de Sevilla, a cuya historiografía nos referiremos en adelante, entre las no muy numerosas publicaciones sobre la historia de aljamas andaluzas en particular, sólo podemos mencionar el trabajo del padre Fidel Fita, escrito a finales del siglo XIX y basado en el análisis de la sinagoga de Córdoba exclusivamente ${ }^{100}$.

\section{LA HISTORIA DE LOS JUDIOOS SEVILLANOS. ESTADO DE LA CUESTIÓN Y PERSPECTIVAS DE LA INVESTIGACIÓN}

A lo largo de los apartados anteriores $-\mathrm{y}$ mediante un vertiginoso recorrido, tal vez - hemos intentado recoger aquellas fuentes y obras, tanto inéditas como publicadas, que, a nuestro entender, pueden servir de utilidad a todos los interesados en el conocimiento o investigación de la historia de los judíos en la Sevilla cristiana.

A partir de ahora, parece conveniente que tratemos de exponer, aunque sea sumariamente, en qué fase se encuentra el estado actual de

95 Cantera Montenegro, Enrique, Las juderías de la diócesis de Calahorra en la baja Edad Media, Biblioteca de Temas Riojanos del Instituto de Estudios Riojanos. Logroño 1986.

96 FITA, Fidel, "La judería de Madrid, 1391 », Boletín de la Real Academia de la Historia, VIII. Madrid 1886. «Datos para la historia de la judería de Madrid», Boletín de la Real Academia de la Historia, X. Madrid 1887. "La judería de Segovia. Documentos inéditos", Boletín de la Real Academia de la Historia, n. ${ }^{\circ}$ IX. Madrid 1886. Ibidem, X. Madrid 1887.

97 ToRRES FONTES, Juan, "Los judíos murcianos en el siglo XIII», Murgetana, n. ${ }^{\circ}$ XVIII. Murcia 1962, págs. 5-20. Molina Molina, Ángel Luis y LaRA Fernández, Francisco de, «Los judíos murcianos en el reinado de Pedro l», Miscelánea Medieval Murciana, V. Murcia 1977, págs. 11-40. TORRES Fontes, Juan, Los judíos murcianos en el reinado de Juan II. Murcia 1965.

98 Collantes de Terán, A., «Grupos marginados», en Historia de Andalucía, III. Madrid-Barcelona 1980, págs. 247-260. BeINART, Haim, Andalucía y sus judíos. Córdoba 1986.

99 Bel. Bravo, María Antonia. Los Reyes Católicos y los judíos andaluces (1474-1492), Universidad de Granada. Granada 1989.

100 FITA, Fidel, "La sinagoga de Córdoba», Boletín de la Real Academia de la Historia, V. Madrid 1884. 
nuestros conocimientos, lo que nos demostrará hasta qué punto los materiales e instrumentos con que contamos han sido utilizados, así como cuáles son las perspectivas de la investigación. Con este fin, intentando basarnos en ciertas obras de síntesis, quizás muy sumarias, trataremos de agrupar los resultados de las investigaciones en algunos apartados fundamentales ${ }^{101}$.

Hasta el momento, conocemos algunas obras relativas en concreto a la historia de la "comunidad judía» sevillana, pero, aunque válidas, resultan ser bastante antiguas, por lo que son más interesantes las noticias que aportan, que los criterios historiográficos con que se redactaron. Entre ellas destacaríamos la de José María Montero de Espinosa, escrita a mediados del siglo $\mathrm{XIX}$, pero reeditada, con un interesante estudio preliminar de Antonio Collantes de Terán, en $1978^{102}$. Y lo mismo puede decirse de la historia de la judería de Sevilla escrita por Mario Méndez Bejarano ${ }^{103}$. Para el antiguo Reino de Sevilla, contamos con algunos trabajos sobre la judería de Jerez dẹ la Frontera, debidos, entre otros, al padre Fidel Fita y a I. Loeb, autores ambos del sigloxIx, y, ya a mitad del siglo xx, a Hipólito Sancho de Sopranis, historiador al que también debemos un estudio sobre la judería del Puerto de Santa María ${ }^{104}$.

En cuanto a los diferentes espacios urbanos ocupados por la «judería sevillana» a lo largo de la Baja Edad Medida, nos son bien conocidos tanto su primitivo y más duradero emplazamiento a raíz de la conquista de la ciudad y del establecimiento de los cristianos en ella, como las temporales y distintas ubicaciones que tuvo a partir del asalto de 1391, cuando, durante el conflictivo siglo $\mathrm{xV}$, el apartamiento de los judíos sevillanos fue decretado en diversas ocasiones. El mejor y más reciente estudio a este respecto, se debe a Antonio Collantes de Terán, en su ya clásico libro sobre la Sevilla de la Baja Edad Media ${ }^{105}$, que resume todos

101 Montes Romero-CAMACHO, Isabel, "Notas para el estudio de la judería sevillana en la Baja Edad Media (1248-1391)", Universidad de Sevilla, Historia. Instituciones. Documentos, n. ${ }^{\circ}$ 10, 1984, págs. 251-277. "La minoría hebrea sevillana a fines de la Edad Media», $V$ Coloquio de Historia Medieval de Andalucía. Córdoba 1988, págs. 551-568.

102 Montero de Espinosa, José María, Relación histórica de la Judería de Sevilla. Sevilla 1849, reed. y estudio de Antonio Collantes de Terán Sánchez, por la Sociedad de Bibliófilos Andaluces. Sevilla 1978.

103 Méndez Bejarano, Mario, Histoire de la juiverie de Séville. Madrid 1922.

104 FITA, Fidel, "Jerez de la Frontera. Su judería en 1266", Boletín de la Real Academia de la Historia, X. Madrid 1887. LoEB, l., "La judería de Jerez de la Frontera. Datos Históricos», Boletín de la Real Academia de la Historia, XII. Madrid 1888. Sancho de Sopranis, Hipólito, "Contribución a la historia de la judería de Jerez de la Frontera», Sefarad, XI. Madrid 1951, págs. 349-370. "La judería del Puerto de Santa María de 1483-1492", Sefarad, XIII. Madrid 1953, págs. 308-323.

105 Collantes de Terán, Antonio, Sevilla en la Baja Edad Media. La ciudad y sus hombres. Sevilla 1977, reed. Sevilla 1984. 
los conocimientos existentes, hasta el momento, sobre los aspectos físicos y urbanísticos de la judería sevillana.

En la actualidad se están llevando a cabo numerosas prospecciones arqueológicas en el ámbito donde estuvo ubicada la antigua judería de Sevilla, en el que habrian de surgir nuevas collaciones cristianas, como consecuencia del asalto de 1391: Santa María la Blanca, Santa Cruz y San Bartolomé el Nuevo, así como restaurándose antiguos edificios situados en estas parroquias $y$, en muchos casos, ya existentes en época judía. Por todo ello, en los próximos años, es de esperar que las fuentes arqueológicas, hasta ahora poco utilizadas, nos aporten nuevos e interesantes datos sobre el tema.

Mientras tanto no nos resistimos a citar algunas viejas obras descriptivas sobre Sevilla, que de seguro, al repasarlas, nos proporcionarán, al menos, curiosas noticias sobre su judería ${ }^{106}$. Más recientemente, es interesante leer la obra miscelánea Historia del urbanismo sevillano, que igualmente trata, en algunos de sus capítulos, sobre este tema ${ }^{107}$. Algunos puntos ya más concretos, como por ejemplo, el cementerio hebreo, fueron estudiados por el padre Fidel Fita, mientras que Francisco Cantera Burgos dedicó cierta atención a los restos epigráficos de los hebreos sevillanos 108 .

La «historia demográfica» de la aljama sevillana nos es conocida, igualmente, gracias a Antonio Collantes de Terán, quien se ha basado, scbre todo, en la documentación conservada en el Archivo Municipal de Sevilla, además de en otras fuentes publicadas al respecto. Sin embargo -y ésta

106 Arana Valflora, F., Compendio histórico descriptivo de la M. N. y M. L. ciudad de Sevilla. Sevilla 1766. GonzÁLEZ DE LEÓN, Félix, Noticia histórica del origen de los nombres de las calles de ésta M. N. y M. L. ciudad de Sevilla. Sevilla 1839 y Noticia artística, histórica y curiosa de todos los edificios públicos, sagrados y profanos de esta M.N. y M.L. y M. H. e invicta ciudad de Sevilla. Sevilla 1844. Alvarez Benavides y López, Manuel, Explicación del Plano de Sevilla; reseña histórico-descriptiva de todas las puertas, calles, plazas. Sevilla 1868. Gestoso y PÉrEZ, José, Curiosidades antiguas sevillanas (serie 1. ${ }^{a}$, Sevilla 1885 y serie 2. ${ }^{a}$, Sevilla 1910), así como Sevilla monumental y artística. Sevilla 1892. Igualmente hay noticias sobre la judería sevillana en la obra del médico converso de la segunda mitad del siglo xIV, Juan de Aviñón, titulada Sevillana Medicina, publicada por el licenciado Nicolás Monardes, en 1545, y de la que contamos con una edición en Sevilla 1885.

107 Historia del urbanismo sevillano, publicada por la Real Academia de Bellas Artes de Santa Isabel de Hungría, patronato "José María Quadrado" del C.S.I.C. Sevilla 1972. Interesan, sobre todo, los capítulos dedicados a la Sevilla Musulmana, por Guerrero LoviLLo, José, y a la Sevilla Mudéjar, por Collantes de Terán Delorme, Francisco.

108 FITA, Fidel, «El cementerio hebreo de Sevilla. Epitafio de un rabino célebre», Boletín de la Real Academia de la Historia, n. ${ }^{\circ}$ XVIl. Madrid 1890. Cantera Burgos, Francisco, «Epigrafía hebraica en Sevilla», Sefarad, n. XI. Madrid 1951 y «Unas palabras más sobre la lápida del médico sevillano R. Sélemo", Sefarad, XII. Madrid 1952. 
no fue la intención del autor, al tratarse su obra de un riguroso análisis de la población total de Sevilla durante los siglos XIV y xV-parece ser que, partiendo de un estudio minucioso de los padrones sevillanos conservados, unidos a las fuentes de Simancas, utilizadas brillantemente por M. A. Ladero Quesada, podrán obtenerse nuevos y más individualizados datos sobre la evolución demográfica de los judíos sevillanos ${ }^{109}$.

Algo similar puede decirse con respecto a las «posiciones socio-económicas» de los hebreos sevillanos al final de la Edad Media. Es verdad que las noticias aportadas por los archivos locales y por el Archivo de Simancas son muy ricas y que han sido utilizadas parcialmente, pero todavía queda mucho por hacer, entre otras cosas un estudio prosopográfico, lo más completo posible, en la medida en que se pueda y que, generalmente, será más fácil — por el mayor número de testimonios que se nos han conservado- en lo que hace a los grandes personajes judíos de la Sevilla cristiana que, muchas veces, por su proximidad a la corona, transcendían el ámbito sevillano.

Algunos de ellos nos son relativamente bien conocidos, incluso a través de obras de síntesis, como las ya citadas de J. Amador de los Ríos, Y. Baer o A. A. Neuman, como, por ejemplo, don Solomón ibn Zadok de Toledo, directamente ligado a Alfonso X, don Yudah Abravanel de Sevilla, verdadero fundador de la potente familia de los Abravaneles y uno de los personajes más influyentes de la corte de Fernando IV, don Yuçaf de Écija, almojarife mayor y hombre de confianza de Alfonso XI; don Samuel haLeví de Toledo, tesorero mayor de Pedro I y que contaba con importantes intereses, además de directos vínculos familiares, en Sevilla. Lo mismo puede decirse con respecto a los Trastámaras, época en que destacan don Yusaph Pichón, contador mayor de Enrique II, o don Samuel Abravanel, que ocupó el mismo cargo con Juan l y que, tras su conversión, tomó el nombre de Juan Sánchez de Sevilla. Sin embargo, hasta la fecha, son muy pocos los estudios monográficos sobre personajes judíos. Sólo podemos citar el de Antonio Ballesteros, publicado en 1946, sobre don Yuãf de Écija ${ }^{110}$.

Por lo que hace a los «marcos institucionales» en los que se desenvolvía la vida de los judíos sevillanos, todo conduce a pesar que este

109 Collantes de Terán, A., Sevilla en la Baja Edad Media. La ciudad y sus hombres. Sevilla 1984. LAdero Quesada, M. A., "Las juderías de Castilla según algunos servicios fiscales el siglo XV», Sefarad, n. ${ }^{\circ} X X X I, 1971$, págs. 249-264.

110 Ballesteros, A., "Don Juçaf de Écija», Sefarad, n. Vi. Madrid-Barcelona 1946, págs. 253-287. 
aspecto de su historia es más fácilmente abarcable, ya que no habría muchas variaciones - en lo que se refiere a la normativa jurídica aplicada a estos hebreos - con respecto a sus demás hermanos de raza, bien se tratase de leyes promulgadas por la Iglesia, la Corona o las autoridades locales. Y lo mismo puede decirse en cuanto a la organización interna, desde el punto de vista jurídico, de la aljama sevillana, que no debió diferir prácticamente en nada de las demás aljamas de Castilla. Igualmente, y por fortuna, se nos han conservado numerosos testimonios de todas estas normativas, como hemos tenido ocasión de reseñar en el apartado correspondiente, dedicado a las fuentes publicadas.

En fin, ya sólo nos queda plantear las actuales deficiencias en el conocimiento de algunos puntos concretos de la historia de los judíos sevillanos al final de la Edad Media. Éstas se observan, sobre todo, en aquellos aspectos que difícilmente dejan testimonios directos, sino que éstos deben ser rastreados indirectamente, como, por ejemplo los cauces por los que discurría la existencia diaria de estos hebreos, especialmente de los más humildes, sus vinculaciones familiares, sus relaciones cotidianas con los cristianos, la posición real que ocupaban en la ciudad, con respecto a los demás poderes urbanos, y, en resumen, todas aquellas noticias que puedan aclarar, en el fondo y en la forma, cómo se desarrollaba, material y espiritualmente, la vida ordinaria de la más importante minoría étnico-religiosa de la Sevilla cristiana.

Pasando ya a la descripción del estado actual de nuestros conocimientos en algunos de los temas que más han atraído el interés de los. investigadores, no sólo por lo que se refiere a la aljama sevillana, sino a todas las de la Península en general, habremos de referirnos, en primer lugar, al Ilamado ""pogromo" mejor asalto de 1391». En este sentido, mencionaremos la obra de carácter general de José M. ${ }^{a}$ Monsalvo Antón sobre el desarrollo del antisemitismo en la Corona de Castilla ${ }^{111}$. Tal vez las verdaderas causas eficientes ael fenómeno, aparezcan con mayor claridad en algunos estudios ya clásicos, como el de Luis Suárez Fernández, acerca de la minoría de Enrique III, y el de Philippe Wolff, referido a las supuestas implicaciones socio-económicas del conflicto ${ }^{112}$.

Ciñéndonos ya al ejemplo concreto sevillano, los antecedentes del asalto a la judería de Sevilla aparecen en algunos trabajos generales,

11 Monsalvo Antón, José M. ${ }^{2}$, Teoría y evolución de un conflicto social: El antisemitismo en la Corona de Castilla en la Baja Edad Media, Siglo XXI. Madrid 1985.

112 Suárez Fernández, L., «Problemas políticos en la minoridad de Enrique Ill», Hispania, XII, 1952, págs. 153-231. WoLFF, Philippe, «The 1391 progrom in Spain. Social crisis or not?», Past and Present, n. ${ }^{\circ}$ 50, 1971, págs. 4-18. 
como el de A. Pons, referido a los judíos de Mallorca, y, sobre todo, el de Julio Valdeón Baruque, acerca de las tensas relaciones entre cristianos y judíos sevillanos en los años precedentes al robo de la judería ${ }^{113}$.

La figura de don Ferrant Martínez, que, como es sabido, jugó un papel clave en el desarrollo de los acontecimientos, está todavía a falta de un estudio en profundidad, ya que sólo contamos con los datos -especialmente su testamento - que publicara Francisco Collantes de Terán, a finales del siglo pasado ${ }^{114}$.

Entre las consecuencias del asalto, las que tenemos mejor estudiadas son aquéllas que se refieren a sus principales beneficiarios, la nueva nobleza trastamarista, gracias, entre otros, al estudio ya venerable, de fray Liciniano Sáez sobre las donaciones efectuadas por Enrique III a los Hurtado de Mendoza y a los Stúñiga, y a las nuevas aportaciones de Fernando Mazo Romero, sobre los Suárez de Figueroa y de M. A. Ladero Quesada sobre los Stúñiga ${ }^{115}$. Estas consecuencias y otras más, han sido resumidas por Antonio Collantes de Terán en un lúcido artículo sobre el destino de los bienes de los conversos sevillanos ${ }^{116}$.

Para concluir con la bibliografía sobre el robo de la judería de Sevilla, en 1391, debemos mencionar algún trabajo de síntesis ${ }^{117}$, así como ciertos testimonios sobre el tremendo efectos que estos sucesos causaron en las demás comunidades judías peninsulares y de fuera de nuestras fronteras ${ }^{118}$. Finalmente, debemos mencionar, como colofón de este apar-

113 Pons, A., "Los judíos del reino de Mallorca durante los siglos XIII y XIV ", Hispania, $\mathrm{n}$. 64, 1956, págs. 163-426. VALDEón BARUQUE, Julio, "Un pleito cristiano-judío en la Sevilla del siglo XIv", Historia. Instituciones. Documentos, 1974, págs. 221-238.

114 Collantes de Terán, Francisco, Memorias históricas de los Establecimientos de Caridad en Sevilla. Sevilla 1884.

115 SAEZ, Fr. Liciniano, Demostración histórica del verdadero valor de todas las monedas que corrian en Castilla durante el reynado de/ señor don Enrique III. Madrid 1796. Mazo Romero, Fernando, "Los Suárez de Figueroa y el Señorío de Feria", Historia. Instituciones. Documentos, n. ${ }^{\circ}$, 1974, págs. 111-164. Ladero QueSADA, Miguel Ángel, “Los señores de Gibraleón", Cuadernos de Historia, n. ${ }^{\circ} 7,1977$, págs. 33-95.

116 Collantes de TERÁN, A., «Un pleito sobre bienes de conversos sevillanos en 1396», Historia. Instituciones. Documentos, n. ${ }^{\circ}$, 1976, págs. 3-18.

117 MONTES ROMERO-CAMACHo, Isabel, "Äntisemitismo sevillano en la baja Edad Media: el pogrom de 1391 y sus consecuencias", Actas del III Coloquio de Historia Medieval Andaluza: La sociedad medieval andaluza: grupos no privilegiados. Jaén 1984, págs. 57-75.

${ }_{118}$ WIENER, M., Sébet Yehudá de r. Selemó ben Verga. Hannover 1856, donde publica la carta de Hasdays Crescas, astrónomo de la reina de Aragón y reputado cronista, a la comunidad judía de Avignon, dándole cuenta de los trágicos sucesos sevillanos de 1391. Existe una traducción española de la crónica hecha por Francisco Cantera: Salomón Ben Verga: "La Vara de Juda", donde la carta aparece en las págs. 274-276, y también la editó KoBLER, F., A treasury of Jewish Letters, vol. I. Filadelfia 1953, págs. 272-275. 
tado, el magnífico estudio de Angus Mackay sobre los «pogroms» castellanos del siglo $x v^{119}$.

Evidentemente una de las consecuencias más inmediatas de los asaltos de 1391 para todas las aljamas españolas y, más concretamente para la sevillana, fue el fenómeno de la «conversión». Por tanto, en primer lugar, tenemos que decir que, el llamado «problema converso» ha suscitado el interés de numerosos e importantes especialistas, entre ellos Francisco Márquez Villanueva ${ }^{120}$ y Eloy Benito Ruano ${ }^{121}$

Por otra parte, las relaciones de los conversos con la Inquisición, han preocupado, entre otros, a Bernardino Llorca, Nicolás López Martínez, Haim Beinart y, ya para los tiempos modernos, a Julio Caro Baroja ${ }^{122}$. Igualmente algunos aspectos concretos, como el denominado «estatuto de pureza de sangre», han llamado la atención, entre otros de B. Netanyahu y A. A. Sichoff ${ }^{123}$, quien también se ha ocupado de la herejía marrana, junto con I. S. Révah ${ }^{124}$, mientras que V. Beltrán de Heredia ha analizado las relaciones del Papado con los conversos castellanos en el siglo $X V^{125}$. De la misma forma, hay otros aspectos peculiares de los

119 Mackay, Angus, «Popular movements and progroms in fifteenth Century Castille», Past \& Present, n. ${ }^{\circ} 55,1972$, págs. 33-67.

120 MÁRQUez VILLANUEVA, Francisco, "The Converso Problem: An Asessment», Collected Studies in Honour of Américo Castro's Eightieth Year. Oxford 1965, págs. 317-333. «El problema de Ios conversos: cuatro puntos cardinales», en el libro Hispania Judaica, ed. por J. M. Solá-Sole, S. G. Armistead y J. H. Silverman, vol. I, Purill. Barcelona 1980, págs. 49-75. Interesan, también, otros estudios de este vol. I: COHEN, Martín A., «Toward a new comprehension of the Marranos», págs. 21-35; NETANYAHU, B., "On the historical meaning of the Hebrew Sources related to the Marranos (a reply to critics)", págs. 77-102 y RIVKIN, Ellis, "How Jewish were the new Christianos?, págs. 103-115.

121 Benito Ruano, Eloy, «El memorial contra los conversos del bachiller Marcos García de Mora (Marquillos de Mazarambroz)", Sefarad, n. ${ }^{\circ}$ XVII, 1957, págs. 314-351. "Del problema judío al problema converso", Simposio Toledo Judaico, vol. II. Toledo 1973, págs. 5-28. Los orígenes del problema converso. Barcelona 1976.

122 LLORCA, Bernardino, "La Inquisición española y los conversos judíos o marranos», Sefarad, n. ${ }^{\circ}$ II, 1942, págs. 113-152. López MARTínez, Nicolás, Los judaizantes castellanos y la Inquisición en tiempo de Isabel la Católica. Burgos 1954. BeINART, Haim, «Conversos on Trial by the Inquisition». Tel Aviv 1965. "The record of the Inquisition: A source of Jewish and Converso History", Proceeding of the /srael Academy of Sciences and Humanities, n. ${ }^{\circ} 2,1967$, págs. 211-2237 y Los conversos ante el tribunal de la Inquisición, Ríopiedras. Barcelona 1983. CARO BAROJA, Julio, Inquisición, brujería y criptojudaismo. Barcelona 1970.

123 Netanyahu, B., "Américo Castro and his view on the origins of the pureza de sangre", Jubilee Volume of the American Academy for Jewish Research. Proceedings, vols. XLVI-XLVII, 1979-1980, págs. 397-457. Sicroff, A. A., Les controverses des statutes de "pureté de sang» en Espagne du 15e au 17e siècle. París 1960.

124 Sicroff, A. A., «The Marranos: Forced Converts or Apostates?», Midstream, n. ${ }^{\circ}$ 12, octubre de 1966, págs. 71-75. REVAH, I. S., «L'hérésie marrane dans J'Europe catholique du 15e au 18e siècle», Hérésies et sociétés dans l'Europe pré-industrielle. París 1968, págs. 327-342.

125 Beltrán de Heredia, V., "Las bulas de Nicolás V acerca de los conversos de Castilla», Sefarad, n. ${ }^{\circ} \mathrm{XXI}, 1961$, págs. 22-47. 
conversos que también han sido muy bien estudiados, como su penetración en los gobiernos municipales, gracias a Francisco Márquez Villanueva ${ }^{126}$; la influencia conversa en la literatura, destacada, por ejemplo, por E. Asensio, o su presencia en las obras literarias, según demostró, entre otros, Francisco Cantera Burgos. Este mismo autor investigó las relaciones entre el famoso cronista real Fernando del Pulgar y los conversos ${ }^{127}$.

Pasando ya a los historiadores que han planteado el tema converso con carácter de síntesis, citaremos, entre otros, a Cecil Roth, I. S. Réva h, B. Netanyahu o H. Beinart ${ }^{128}$, mientras que la problemática de los «cristianos nuevos", ya en la Edad Moderna, encontró su historiador en Antonio Domínguez Ortiz ${ }^{129}$.

Igualmente, existen algunos repertorios bibliográficos que recogen numerosas publicaciones sobre los conversos, por lo que son muy útiles antes de iniciar cualquier tipo de investigación concreta sobre los mismos. Citaremos, por orden cronológico, los de A. Domínguez Ortiz, G. Nahon o B. Netanyahu ${ }^{130}$.

126 Márquez Villanueva, Francisco, «Conversos y cargos concejiles en el siglo xV ", Revista de Archivos, Bibliotecas y Museos, n. ${ }^{\circ}$ LXIII-1, 1957, págs. 503-540. En cuanto a su papel en la corte de los reyes Católicos ver: Rábade ObRadó, M. a del Pilar, Los judeoconversos en la corte y en la época de los Reyes Católicos. Edición de la Universidad Complutense. Madrid 1990. Una sintesis más reciente de la misma autora. Una élite de poder en la corte de los Reyes Católicos. Los judeoconversos. Sigilo. Madrid 1993.

127 AsENSIO, E., “La peculiaridad literaria de los conversos", Anuario de Estudios Medievales, n. IV, 1967, págs. 327-351. CANTERa Burgos, Francisco, «El cancionero de Baena: judíos y conversos en él», Sefarad, n. ${ }^{\circ}$ XXVII, 1967, págs. 71-111. "Fernando del Pulgar y los conversos», Sefarad, n. ${ }^{\circ} \mathrm{V}, 1944$, págs. 295-348.

${ }_{128}$ Roth, Cecil, A History of the Marranos, publicada por primera vez en Filadelfia 1932. Hay una buena traducción española: Los judios secretos: Historia de los Marranos, en Ed. Altalena. Madrid 1979. ReVAH, I. S., “Les Marranes", R.E.J., n. CXVIII, 1959-1960, págs. 29-77. NETANYAHU, B., The marranos of Spain from the Late XIVth to the Early XVIth Century, American Academy for Jewish Research. Nueva York 1966, nueva edición en Kraus Reprint Co. Millwood. Nueva York 1973. BEINART, Haim, «The Converso Community in 15th Century Spain» $y$ «The Converso Community in 16th and 17th Century Spain", en el libro The Sephardi Heritage, vol. I, Valentine \& Mitchell. Londres 1971, págs. 425-456 y 457-478.

129 Domínguez Ortiz, A., «Los cristianos nuevos. Notas para el estudio de una clase social», Boletín de la Universidad de Granada, n. ${ }^{\circ}$ LXXXVII, 1949, págs. 249-297. La clase social de los conversos en Castilla en la Edad Moderna. Madrid 1955, Los judeoconversos en España y América, Istmo. Madrid 1971.

130 Domínguez Ortiz, A., «Historical Research on Spanish Conversos y in the last 15 years", Collected Studies in Honour of Américo Castro's Eightieth Years. Oxford 1965. NAHON, G., "Les Marranes espagnoles et portugais et les communautés issues du marranísme dans l'historiographie récente (1960-1975)», R.E.J., n. ${ }^{\circ}$ CXXXVI, 1977, págs. 297-367. NeTANYAHU, B., «On the historical meaning of the Hebrew sources related to the Marranos», Hispania Judaica, ed. J. M. Solá-Solé, S. G. Armistead, J. H. Silverman. Barcelona 1980, págs. 79-102. 
Pero éstas son, en su mayoría, obras generales sobre el grupo social de los conversos hispanos. Ahora es conveniente que nos refiramos al caso de los judeoconversos andaluces y, más concretamente, de los sevillanos. Hoy por hoy, el mejor historiador de los judeoconversos andaluces es, sin duda, Miguel Ángel Ladero Quesada, tanto por sus trabajos publicados, como por los que aún no están impresos o se encuentran en vías de preparación ${ }^{131}$. En casi todos ellos se han aprovechado minuciosamente las fuentes simanquinas, lo que ha permitido el conocimiento de numerosos aspectos de la vida de los judeoconversos andaluces en general y sevillanos en particular, llegándose, incluso, a intentos prosopográficos. Ya para Sevilla, otros trabajos de interés son los de Claudio Guillén, que permite el estudio de los conversos sevillanos a comienzos del siglo $x v^{132} y$, también, el muy minucioso de José Antonio Ollero Pina, sobre la importante familia conversa sevillana de los Benadeva ${ }^{133}$. Por su parte, A. Domínguez Ortiz, ha estudiado el Estatuto de los hijos y nietos de condenados, de 1515, inserto en las Constituciones de la Catedral de Sevilla ${ }^{134}$. Por último citaremos algún trabajo concreto sobre individuos de origen converso; que, hasta la fecha, no son muy abundantes ${ }^{135}$.

Otro asunto importante al que debemos hacer mención, sin ningún tipo de excusa, es el de la «Inquisición", sobre todo si tenemos en cuenta que fue en Sevilla donde se estableció por primera vez este tribunal, en su segunda época, y donde, por orden de los Reyes Católicos, comenzó sus

131 LADERO QUESADA, Miguel Ángel, Judeoconversos andaluces en el siglo XV", / Coloquio Internacional de Encuentro de las Tres Culturas. Toledo 1983. "Judeoconversos andaluces en el siglo Xv", III Coloquio de Historia Medieval Andaluza: La sociedad medieva andaluza: grupos no privilegiados. Jaén 1984, págs. 27-55. "Los conversos de Córdoba en 1497», El Olivo, n. ${ }^{\circ}$ XIII/29-30,1989, págs. 187-205. Entre sus trabajos en imprenta, citaremos la ponencia presentada el congreso celebrado en Ribadavia, en octubre de 1991, titulada «Sevilla y los conversos; los "habilitados" en 1495" y su aportación al congreso mundial sobre la expulsión de los judíos, que tuvo lugar en Jerusalén, en enero de 1992, cuyo título es "Judíos y judeoconversos en Andalucía. 1481-1508».

132 GUILLÉN, Claudio, «Un padrón de conversos sevillanos», Bulletín Hispanique, $n .{ }^{\circ}$ LXV, 1963, págs. 49-98.

${ }_{133}$ Ollero PINA, José Antonio, uUna familia de conversos sevillanos en los orígenes de la Inquisición: Los Benadeva», en Hispania Sacra, n. ${ }^{\circ}$ 40, 1988, págs. 43-105.

134 Domínguez Ortiz, A., "La clase social de los conversos en Castilla en la Edad Moderna», Estudios de Historia Social de España, n. ${ }^{\circ}$ III, 1960, este estatuto estaba recogido en los "Estatutos y Constituciones de esta Sancta Yglesia de Sevilla (...), copia manuscrita autorizada por Fernando de Torres, notario apostólico de Sevilla, a 28 de mayo de 1598 (Biblioteca Capitular y Colombina de Sevilla, ms. 85-8-16).

135 Sancho de Sopranis, H., "Charles de Valera", Hispania, n. ${ }^{\circ} \mathrm{XI}, 1951$, págs. 413-540, se trataba de un alcaide del Puerto de Santa María, que jugó un papel importante no sólo a nivel de política local, sino en todo lo referente a la expansión ultramarina de la segunda mitad del siglo $\mathrm{xv}$. 
actuaciones en 1481. Una vez más, la ciudad andaluza se situaba a la vanguardia de todo lo relacionado con la minoría hebrea.

Como es sabido, se trata de un tema cargado de polémica, por lo que ha venido preocupando a numerosos investigadores, antiguos y modernos, nacionales y extranjeros, que se han ocupado de él desde los más diversos puntos de vista. Entre ellos citaremos algunas obras generales sobre su nacimiento, así como una guía bibliográfica, bastante completa, aunque algo anticuada ${ }^{136}$. Hay también algunos libros de interpretación sobre el papel de la Inquisición y su influencia en la mentalidad hispana ${ }^{137}$.

Pero, tal vez, los trabajos más dignos de reseñar sean aquéllos que se refieren particularmente al análisis de la Inquisición como hecho histórico, entre los que se encuentran algunos de gran calidad, ya sea por la aportación de datos, o por su condición de síntesis interpretativa. Entre los autores más destacados, citaremos a Bernardino Llorca, quien con un carácter casi pionero, no sólo recopiló la documentación pontífica relativa a la Inquisición española, desde su fundación hasta el primer cuarto del siglo XVI, sino que publicó importantes trabajos, referidos, sobre todo, a los primeros tiempos de esta institución ${ }^{138}$. Un sentido parecido pueden tener las obras de J. A. Llorente, Miguel de la Pinta, A. S. Turberville y S. W. Baron ${ }^{139}$.

Por su parte, la moderna historiografía sobre la Inquisición se inicia, al parecer, con Henri Kamen, cuya obra, considerada como clásica, ha sido reeditada en varias ocasiones ${ }^{140}$. Igualmente, se ha ocupado del

136 Maisonneuve, H., Etudes sur les origines de l'Inquisition. París 1960. Van Der Vekene, E., Bibliographie der Inquisition. Ein Versuch. Hildesheim 1963.

137 PINTA, M. de la, La Inquisición española y los problemas de la cultura y de la intolerancia. Madrid 1953. Attafd Palacio, V., Razón de la Inquisición. Madrid 1964. Alcalá Gálvez, A. y otros, Inquisición y mentalidad inquisitorial, Ariel. Barcelona 1984.

138 LLORCA, Bernardino, «Bulario pontificio de la Inquisición española en su período constitucional (1478-1525)", Miscelanea Historiae Pontificae, vol. XV, Colletionis totius, $\mathrm{n}{ }^{\circ}$ 48. Roma 1949. «La Inquisición española incipiente», Gregorianum, n. ${ }^{\circ}$ XX, 1939, págs. 101-142 y 507534. La Inquisición en España. Barcelona 1936. La Inquisición Española, Universidad Pontificia de Comillas (Santander), 1953.

139 LlORENTE, J. A., Histoire critique de l'Inquisition d'Espagne. París 1917, magna obra que ha merecido una reedición en castellano hace ya algunos años: Historia crítica de la Inquisición en España, 4 vols. Madrid 1980. PINTA, Miguel de la, O.S.A., La Inquisición española. Madrid 1948, así como algunos aspectos más concretos: The Spanish Inquisition. Londres 1949. TuRBerville, A. S., The Spanish Inquisition. Londres 1949, traducción española: La Inquisición española, 5. ${ }^{a}$ ed. México 1965. BARON, S. W., "A Social and Religious History of the Jews", 2." ed. Nueva York 1952. Ver Iberian Inquisition, en el vol. XIII.

140 KAMEN, Henri, The Spanish Inquisition. Londres 1965. La primera traducción española en Barcelona, 1967; otra en Crítica, Barcelona 1979 y en Grijalbo, Barcelona 1985. 
problema, en un enorme esfuerzo de síntesis, otro gran especialista sobre los judíos, Luis Suárez Fernández ${ }^{141}$. Más modernamente, además de algún que otro estudio de conjunto, citaremos los de reconocidos autores como B. Bennassar, quien ha intentado hacer un análisis completo de toda la época histórica de la Inquisición, y el muy reconocido libro de $\mathrm{H}$. Ch. Lea $^{142}$.

En otro orden de cosas, J. Pérez Villanueva y Bartolomé Escandel Bonet son los directores de una ambiciosa obra sobre la Inquisición española y americana ${ }^{143}$. Igualmente han tratado el tema, entre otros, J. A. Escudero $y$, con un sentido de difusión y carácter general, R. García Cárcel ${ }^{144}$. De la misma manera, citaremos, como modelo, algún estudio de un judaizante, en particular ${ }^{145}$.

Llegamos ya al análisis de la actuación de la Inquisición en Sevilla. Para ello contamos con algunas obras de importancia, como la ya citada de José María Montero de Espinosa, que, a pesar de su antigüedad, quizás sea la que aporte mayor número de datos sobre el problema ${ }^{146}$. Aparte de esto, sólo contamos con algunos trabajos de síntesis, casi todos muy valiosos, pero, tal vez, no demasiado ricos en detalles, debido a la escasa documentación directa conservada sobre la Inquisición sevillana. Así pues, merece la pena que citemos, el estudio de Juan de Mata Carriazo, sobre sus rentas, el de Klaus Wagner, basado fundamentalmente en la documentación de protocolos notariales, acerca de la primera época de la Inquisición en Sevilla, o los nuevos datos aportados por Eduardo

141 Suárez Fernández, L., "La Inquisición", en Historia de España, ed. R. Menéndez Pidal, vol. XVII, 2. Madrid 1969, págs. 209-240.

142 La Inquisición Española. Nueva Visión, nuevos horizontes. Director del volumen Joaquín Pérez, Villanueva (Madrid 1980). Bennassar, B., L'Inquisition Espagnole XV-XIxe siècles. París 1979, traducción española: La Inquisición española (siglos XV-XIX), Crítica. Barcelona 1982. LEA, H. Ch., Historia de la Inquisición Española. Madrid 1983. La obra de síntesis más reciente quizá sea la de CARRETE, Carlos, El judaísmo español y la Inquisición. "Colecciones Mapfre. 1492". Madrid 1992.

143 PÉrez Villanueva, J. y Escandel Bonet, Bartolomé (dirs.), Historia de la Inquisición en España y América, Biblioteca de Autores Cristianos y Centro de Estudios Inquisitoriales. Madrid 1984.

144 Escudero, J. A., «La Inquisición en España», Cuadernos de Historia, 16, n. 108. Madrid 1985. GARCIA CÁRCEL, R., La Inquisición, Colección Básica de Historia, Monografía, Anaya. Madrid 1990.

${ }_{145}$ Sicroff, A. A., «El caso del judaizante jerónimo fray Diego de Marchena», Homenaje a Rodríguez Moñino, vol. Il. Madrid 1969, págs. 227-233.

146 Montero de Espinosa, José María, Relación Histórica de la Judería de Sevilla, Establecimiento de la Inquisición en ella, su estinción, y colección de los autos que llamaban de fe celebrados desde su erección, Sociedad de Bibliófilos Andaluces. Valencia 1978, con un estudio preliminar de Antonio Collantes de Terán. 
Aznar Vallejo, a partir de documentos conservados en la Biblioteca Nacional de París ${ }^{147}$.

Por último, mencionaremos algunos trabajos sobre ciertos hechos concretos, como el de Fidel Fita, en torno a la famosa conjura conversa contra la Inquisición sevillana, en 1480, o el de David Kaufmann, sobre un auto de fe, celebrado en Sevilla, en $1501^{148}$.

Sólo nos queda añadir que esta falta de estudios en profundidad sobre la Inquisición sevillana, está perfectamente justificado por la ausencia, casi total, de fuentes directas sobre tan importante institución y su actuación en Sevilla.

Finalmente, nos referiremos al último capítulo de la historia de los judíos españoles, la «expulsión». Como es sabido, éste fue un fenómeno general que afectó a todos los hebreos peninsulares, por lo que el caso de la expulsión de los judíos sevillanos debe ser encuadrado en este contexto general. De todas maneras, una vez más, aparecen rasgos peculiares, como el hecho de que fuese Sevilla la primera ciudad del reino donde se decretó su destierro, exactamente en 1483. Esta precocidad ha sido justificada de las más diversas maneras. Entre otras, últimamente, se le ha tratado de dar una explicación de tipo ideológico, basándose en la mentalidad apocalíptica y mesiánica que supuestamente impregnaba a la sociedad andaluza de la época. En este sentido, se expresan autores como Angus Mackay y Manuel González Jiménez ${ }^{149}$.

Pero donde se nota un mayor vacío es en el aporte de datos concretos de análisis que puedan explicar el fenómeno, en un sentido general y que permitan elaborar una buena síntesis. A este respecto, siempre es ne-

147 Carriazo y Arroquia, Juan de Mata, «La Inquisición y las rentas de Sevilla», en Homenaje a don Ramón Carande, vol. II. Madrid 1963, págs. 95-112. WAGNER, Klaus, «La Inquisición en Sevilla (1481-1524). Notas al margen de las Actas Notariales del Archivo de Protocolos de Sevilla, referentes a los Autos de Fe celebrados en dicha Ciudad", Homenaje al Prof. Carriazo, tomo III, Facultad de Filosofía y Letras, Publicaciones de la Universidad. Sevilla 1973, págs. 441-460. AzNar VALlejo, E., "Nuevos datos sobre los orígenes de la Inquisición en Sevilla", $V$ Coloquio Internacional de Historia Medieval de Andalucía. Córdoba 1988, págs. 569-580.

148 FITA, Fidel, "Historia Hebrea. Documentos y monumentos inéditos. Los conjurados de Sevilla contra la Inquisición en 1480», Boletín de la Real Academia de la Historia, n. ${ }^{\circ} 16,1890$, págs. 450-456 y "Los conjurados de Sevilla en 1480. Relación de Cristóbal Núñez», págs. 555560. Kaufmann, David, "L'autodafé des quarente-cinq martyrs de Séville en 1501», Revue des études juives, XXXVIII, 1899.

149 Mackay, Angus, "Andalucía y la guerra del fin del mundo», Actas del V Coloquio Internacional de Historia Medieval Andaluza. Andalucia entre Oriente y Occidente (1236-1492). Córdoba 1988, págs. 329-342. GonzÁLEZ JIMÉNEZ, Manuel, «El fracaso de la convivencia. Moros y judios en Andalucía (siglos X|H-XV)", en Proyección Histórica de España en sus tres culturas (Castilla y León, América y el Mediterráneo). Medina del Campo, abril de 1991 (en prensa). 
cesario acudir a los ricos corpus documentales del reinado de los Reyes Católicos, publicados por Antonio de la Torre y Luis Suárez Fernández y, sobre todo, más concretamente, a la, utilísima y única en su género, obra de este último, que reúne la documentación relativa, en concreto, a la expulsión de los judíos ${ }^{150}$.

Entre las obras de síntesis sobre la expulsión de los judíos, citaremos algunas ya antiguas, pero que aún conservan cierta frescura e interés, como las de A. Marx ${ }^{151}$. Pero, para el caso castellano, contamos con grandes estudios, aunque no sean monográficos sobre el tema, como el de Tarsicio de Azcona o el de Luis Suárez Fernández ${ }^{152}$.

También han sido varias las explicaciones que se han querido dar a este hecho, algunas de las cuales fueron recogidas por M. Kriegel, aunque otros, como S. H. Haliczer prefieren ver ciertas motivaciones más concretas, como la posible influencia de un patriciado urbano en ascenso, cerca del ánimo de los monarcas, que habría podido actuar en defensa de sus intereses ${ }^{153}$.

El destino posterior de estos judíos, bien fuese América o el mundo mediterráneo, también ha interesado a algunos historiadores, como es el caso de M. Serrano y Sanz, de Antonio Domínguez Ortiz, de Maurice Kriegel o de Henry Kamen ${ }^{154}$. Y por último, la consecuencia final de la ex-

150 TorRe, Antonio de la y SuÁREZ FERnÁndez, Luis, Documentos referentes a las relaciones con Portugal durante el reinado de los Reyes Católicos. Valladolid 1958. Torre, Antonio de la, Documentos sobre las relaciones internacionales de los Reyes Católicos. Barcelona 1962. SUÁREz Fernández, Luis, Documentos acerca de la expulsión de los judios. Valladolid 1964.

151 MARX, A., "The expulsion of the Jews from Spain. Two new accounts", J.Q.R., m.S. XXX, 1908, págs. 240-271. "Additions and Corrections", J.Q.R., n.s. II, 1911, págs. 257-258 y Studies in Jewish History and Booklore. Nueva York 1944.

152 Azcona, Tarsicio de, Isabel la Católica. Estudio crítico de su vida y su reinado. Madrid 1964. SuÁREZ Fernández, Luis, "La expulsión de los judíos», en Historia de España, ed. de Ramón Menéndez Pidal, vol. XVII, 2. Madrid 1969, págs. 241-264. Hace poco tiempo, este último autor ha publicado una interesante monografía sobre el tema: La expulsión de los judios de España, «Colecciones Mapfre 1492. Madrid, 1991. Un ejemplo concreto en CANTERA MonTENEGRO, Enrique, «Judíos y conversos en Torrelaguna (Madrid) en tiempos de la expulsión», en $L a$ España Medieval, II-I, Publicaciones de la Universidad Complutense de Madrid, 1982, págs. 233252.

${ }^{153}$ KRIEGEL, M., "La prise d'une décision: l'expulsion des juifs d'Espagne en 1492", Revue Historique, n. ${ }^{\circ} \mathrm{CCLX}, 1978$, págs. 49-90. Haliczer, S. H., "The Castilian Urban Patriciate and the Jewish Expulsions of 1480-1492", American Historical Review, n. ${ }^{\circ}$ LXXVIII, 1973, págs. 3558.

154 Serrano y Sanz, M., Orígenes de la dominación española en América. Madrid 1918. Domínguez Ortiz, Antonio, Los judeoconversos en España y América. Madrid 1971. KRIEGEL, Maurice, Les juifs dans le monde mediterranéen a la fin du Moyen Age. París 1979. KamEN, Henry, "The Mediterranean and the Expulsion of Spanish jews in 1492 " Past \& Present, $n .{ }^{\circ} 119$, mayo de 1988, págs. 30-55. 
pulsión, el nacimiento del mundo sefardí, ha sido analizada por un especialista de la talla de Haim Beinart ${ }^{155}$.

\section{CONCLUSIÓN}

A lo largo de este vertiginoso recorrido a través de las fuentes y la bibliografía que, en nuestros días, existen para el estudio de la aljama sevillana en la Baja Edad Media, hemos podido constatar el tremendo esfuerzo de numerosas generaciones de historiadores -algunos de los cuales eran incluso contemporáneos a los hechos-por intentar desentrañar la historia de los judíos de Sevilla. Gracias a ellos, es mucho lo que se ha logrado, pero todavía queda un largo camino por andar, sobre todo en lo que se refiere a la documentación e interpretación de algunos aspectos y hechos concretos. Pero, a pesar de ello, lo que más se echa en falta es una buena síntesis sobre la historia de la judería sevillana al final de la Edad Media, así como la publicación de un corpus documental, lo más completo posible, que sirva de instrumento básico a cualquier tipo de investigación.

Indiscutiblemente, es mucho lo que se ha conseguido, pero, teniendo en cuenta las importantes deficiencias mencionadas con anterioridad, podríamos afirmar, tomando palabras de Baer, que la historia de los judíos en la Sevilla cristiana, está aún por hacer.

155 BEINART, Haim, "La formación del mundo sefardi", Actas del primer Simposio de Estudios Sefardies. Madrid 1970. 